\title{
The transcription factor Nerfin-1 prevents reversion of neurons into neural stem cells
}

\author{
Francesca Froldi, ${ }^{1,2,6}$ Milan Szuperak, ${ }^{1,2,6}$ Chen-Fang Weng, ${ }^{1,2}$ Wei Shi, ${ }^{3,4}$ Anthony T. Papenfuss, ${ }^{1,2,3,5}$ \\ and Louise Y. Cheng ${ }^{1,2}$ \\ ${ }^{1}$ Peter MacCallum Cancer Centre, East Melbourne, Victoria 3002, Australia; ${ }^{2}$ Sir Peter MacCallum Department of Oncology, \\ University of Melbourne, Parkville, Victoria 3010, Australia; ${ }^{3}$ Bioinformatics Division, The Walter and Eliza Hall Institute of \\ Medical Research, Parkville, Victoria 3052, Australia; ${ }^{4}$ Department of Computing and Information Systems, The University of \\ Melbourne, Parkville, Victoria 3010, Australia; ${ }^{5}$ Department of Medical Biology, University of Melbourne, Melbourne, Victoria \\ 3010, Australia
}

Cellular dedifferentiation is the regression of a cell from a specialized state to a more multipotent state and is implicated in cancer. However, the transcriptional network that prevents differentiated cells from reacquiring stem cell fate is so far unclear. Neuroblasts (NBs), the Drosophila neural stem cells, are a model for the regulation of stem cell self-renewal and differentiation. Here we show that the Drosophila zinc finger transcription factor Nervous fingers 1 (Nerfin-1) locks neurons into differentiation, preventing their reversion into NBs. Following Prospero-dependent neuronal specification in the ganglion mother cell (GMC), a Nerfin-1-specific transcriptional program maintains differentiation in the post-mitotic neurons. The loss of Nerfin-1 causes reversion to multipotency and results in tumors in several neural lineages. Both the onset and rate of neuronal dedifferentiation in nerfin-1 mutant lineages are dependent on Myc- and target of rapamycin (Tor)-mediated cellular growth. In addition, Nerfin-1 is required for NB differentiation at the end of neurogenesis. RNA sequencing (RNA-seq) and chromatin immunoprecipitation (ChIP) analysis show that Nerfin-1 administers its function by repression of selfrenewing-specific and activation of differentiation-specific genes. Our findings support the model of bidirectional interconvertibility between neural stem cells and their post-mitotic progeny and highlight the importance of the Nerfin-1-regulated transcriptional program in neuronal maintenance.

[Keywords: stem cells; neuroblasts; cancer; dedifferentiation; Drosophila; central nervous system]

Supplemental material is available for this article.

Received August 11, 2014; revised version accepted December 1, 2014.

Dedifferentiation is a cellular process by which a partially or terminally differentiated cell reverts to a less differentiated, more multipotent state. The bidirectional conversion between differentiated cells and cancer stem cells often underlies carcinogenesis. For example, it was recently demonstrated that glioblastoma multiforme can originate from terminally differentiated cortical astrocytes and neurons via the combined loss of NF1 and P53 (Friedmann-Morvinski et al. 2012). A combination of oncogenic hits, such as activated Kras and activation of NF-kB, has also been shown to lead to the conversion of nonstem intestinal epithelial cells into cells with stem cell properties in intestinal tumors (Schwitalla et al. 2013). Therefore, it appears that dedifferentiated cells could be the cellular origin of certain cancers, but the transcriptional programs that regulate the initiation of this event remain unclear. Furthermore, in a wild-type developmental context, although many

${ }^{6}$ These authors contributed equally to this work. Corresponding author: louise.cheng@petermac.org

Article is online at http://www.genesdev.org/cgi/doi/10.1101/gad.250282.114. factors have been implicated in promoting stem cell differentiation, less is known about the mechanisms that render differentiated cells incapable of re-entering the cell cycle.

In the Drosophila CNS, type I stem cell-like neural progenitors, the neuroblasts (NBs) (Fig. 1A, red), divide asymmetrically, producing one large daughter cell that self-renews and a second, smaller daughter cell-the ganglion mother cell (GMC) - that divides only once to give rise to two terminally differentiating neuronal or glial cells (Fig. 1B; for review, see Homem and Knoblich 2012). In addition to the type I NBs, eight bilateral type II NBs are located in the central brain (Fig. 1A, blue) that divide to selfrenew and generate smaller intermediate neural progenitors (INPs), which in turn undergo asymmetric divisions to

(C) 2015 Froldi et al. This article is distributed exclusively by Cold Spring Harbor Laboratory Press for the first six months after the full-issue publication date (see http://genesdev.cshlp.org/site/misc/terms.xhtml). After six months, it is available under a Creative Commons License (Attribution-NonCommercial 4.0 International), as described at http:// creativecommons.org/licenses/by-nc/4.0/. 
A
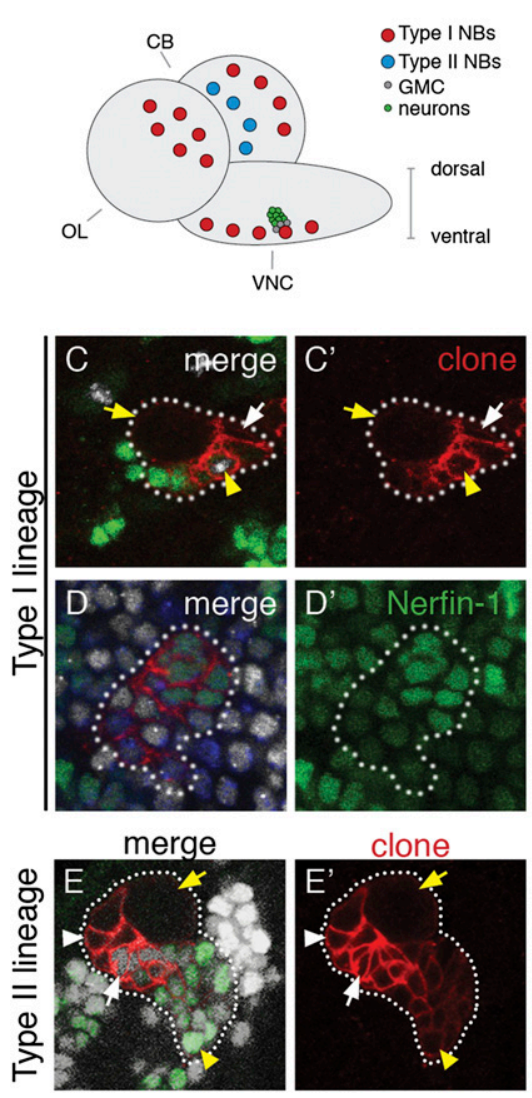

B
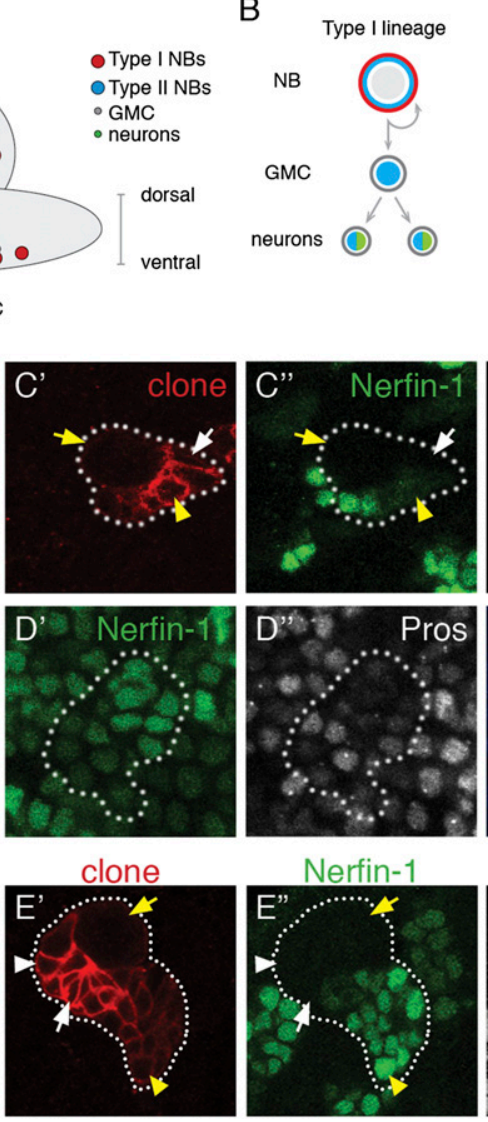

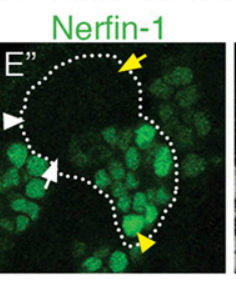

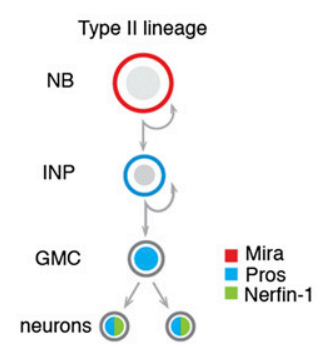
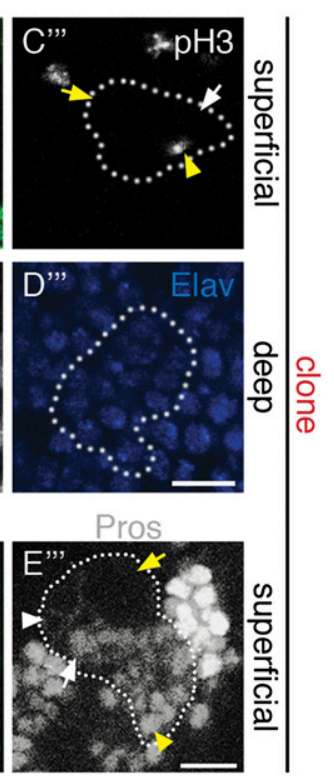

Figure 1. Nerfin-1 expression during postembryonic neurogenesis. (A) Larval CNS is generated by type I (red) and type II (blue) neuroblasts throughout post-embryonic neurogenesis. The earliest born neurons are located deep in the CNS, and the most recently born neurons are located superficially. $(B)$ Schematics depicting neurogenesis in type I and type II lineages. Type I NBs express Mira and segregate Pros to the GMC. GMCs divide only once to produce two post-mitotic neurons that express Nerfin-1. Type II NBs divide to self-renew and give rise to transit-amplifying INPs. Type II NBs express Mira but not Pros. INPs divide four to eight times, generating another INP and a GMC that divides only once to give rise to two neurons, both of which express Nerfin-1. $\left(C-D^{\prime \prime \prime}\right)$ Type I MARCM clone marked by RFP. $\left(C-C^{\prime \prime \prime}\right)$ Superficial section: Nerfin-1 (green) is absent in the NB (yellow arrow) and in the latest born GMCs adjacent to the $\mathrm{NB}$ (white arrow) and is expressed at low levels in mitotic GMCs (positive for the mitotic marker $\mathrm{pH}^{+}$; yellow arrowhead). (D-D"') In a deep section of the clone, Nerfin-1 colocalizes with Pros (white) and Elav (blue) in differentiated neurons. (E-E'I') Type II lineage marked by RFP. Nerfin-1-GFP (green) is expressed in post-mitotic neurons (yellow arrowhead) but not in type II NBs (large cell; yellow arrow) or INPs (identified by cortical Pros; white in $E^{\prime \prime \prime}$; white arrowhead) and at very low levels in GMCs (identified by nuclear Pros; white arrow). Bars, $10 \mu \mathrm{m}$. See also Supplemental Figures S1-S3. self-renew and give rise to GMCs and neurons (Fig. 1B; Bello et al. 2008; Boone and Doe 2008; Bowman et al. 2008).

At each NB division, cell fate determinants such as Prospero (Pros) (Doe et al. 1991; Vaessin et al. 1991), Brain tumor (Brat) (Bello et al. 2006; Betschinger et al. 2006), and Numb (Rhyu et al. 1994) are segregated from the NB into the GMC. These fate determinants inhibit selfrenewal, direct cell cycle exit, promote neuronal differentiation, and prevent tumor formation. Pros has been shown to act as a transcriptional switch primarily in the GMCs to repress genes required for self-renewal such as Miranda (Mira), Asense (Ase), and Deadpan (Dpn) and activate genes for neuronal and glial differentiation (Fig. 1B, blue; Choksi et al. 2006). In the absence of Pros, GMCs fail to differentiate, revert to NBs, and form brain tumors in both type I and type II NB lineages /Caussinus and Gonzalez 2005; Bello et al. 2006; Betschinger et al. 2006; Choksi et al. 2006; Lee et al. 2006b; Maurange et al. 2008). However, while these studies have led to a good understanding of how neural progenitors give rise to neurons, it is not yet clear what factors are required to maintain neuronal differentiation. Recently, the RNA splicing factor midlife crisis (mlc) (Carney et al. 2013) and the BTB-zinc finger transcription factor Lola (Southall et al. 2014) have been implicated in neuronal maintenance. $m l c$ regulates Pros expression, and its loss causes neuron-to-NB reversion.
However, loss of Pros alone was not sufficient to induce neuronal dedifferentiation, and, furthermore, the reverted NBs in mlc mutants are stalled in the cell cycle and do not form tumors. Lola, on the other hand, is a Pros cofactor and acts redundantly with Pros. Loss of Lola was sufficient to cause neuron-to-NB reversion only in the optic lobe regions of the CNS where Pros is absent (Southall et al. 2014). To date, no general factor that regulates neuronal maintenance preventing dedifferentation and tumor formation in type I and II NB lineages has been found.

Here we show that Nervous fingers 1 (Nerfin-1), a zinc finger transcription factor previously implicated in embryonic axon guidance in Drosophila (Stivers et al. 2000; Kuzin et al. 2005), is expressed in the post-mitotic larval neurons and maintains their differentiated status. In the absence of Nerfin-1, neurons dedifferentiate, rapidly increase in size via Myc- and target of rapamycin (Tor)-dependent mechanisms, and undergo reversion to acquire a NB cell fate, ultimately resulting in proliferative neural tumors. Using complementary approaches of RNA sequencing (RNA-seq) and chromatin immunoprecipitation (ChIP), we found that Nerfin-1, like Pros, promotes differentiation and represses self-renewal. Unlike Pros, however, Nerfin-1, rather than acting in the GMC, primarily activates a transcriptional program in neurons to maintain their differentiated state. Furthermore, we demonstrate that Nerfin-1 is required for 
NB terminal differentiation at the end of neurogenesis, and its overexpression causes premature NB loss.

\section{Results}

Nerfin-1 is expressed in neurons derived from type I and type II NB lineages

The larval CNS is generated during post-embryonic neurogenesis by both type I and type II NBs (Fig. 1A,B). We investigated the localization of Nerfin-1 protein in both lineages using a transgene expressing a Nerfin-1-GFP fusion protein under control of the nerfin-1 promoter (referred to as Nerfin-1-GFP) that was previously generated to study nerfin-1 post-transcriptional silencing (Kuzin et al. 2007). We found that Nerfin-1-GFP recapitulates the expression pattern of the Nerfin-1 antibody (Supplemental Fig. S1A-A"), validating it as a bona fide tool to follow Nerfin-1 expression pattern. Nerfin-1-GFP was found to be expressed in a subset of neurons (which also express the neuronal marker Pros) (Spana and Doe 1995) at $36 \mathrm{~h}$ after larval hatching (ALH) (Supplemental Fig. S2A-B"'). By 72 h ALH (Supplemental Fig. S2C-D"') and 96 h ALH (Supplemental Fig. S2E$\left.\mathrm{F}^{\prime \prime \prime}\right)$, most neurons expressed both Pros and Nerfin-1GFP.

The mature neurons generated by NBs lie deep within the CNS at a location several cell diameters away from the parental NB, while newly born neurons are found more superficially. In superficial sections, we found that Nerfin-1-GFP was absent from type I NBs (Fig. 1C-C"', yellow arrow; Supplemental Figs. S1B-B", S3A-C", white arrow; Supplemental Movie S1) and early born GMCs (Fig. 1C-C"', white arrow; Supplemental Fig. S3C-C", yellow arrow). However, it was detected at low levels in mature, dividing GMCs (Fig. $1 \mathrm{C}-\mathrm{C}^{\prime \prime}$, yellow arrowhead, positive for the mitotic marker phospho-Histone H3 [pH3]). In deep sections, Nerfin-1-GFP was expressed in all post-mitotic neurons marked by the expression of the neuronal markers Pros and embryonic lethal abnormal vision (Elav) (Fig. 1D$\left.\mathrm{D}^{\prime \prime \prime}\right)$. Type II NBs produce INPs that undergo several self-renewing divisions to amplify the number of progeny (Fig. 1B). In type II lineages, Nerfin-1 was also expressed in Pros-expressing neurons (Fig. 1E-E"', yellow arrowhead) and at low levels in mature GMCs (Fig. 1E$E^{\prime \prime \prime}$, white arrow, nuclear Pros ${ }^{+}$cells adjacent to the INPs) but not in NBs (Fig. 1E-E"', yellow arrow, distinguished by its large size) or INPs (Fig. 1E-E"', white arrowhead, cortical Pros localization). Altogether, in both type I and type II lineages, Nerfin-1 expression is associated with differentiated rather than self-renewing cells.

nerfin-1 loss-of-function generates neural tumors in type $I$ and type II lineages

In order to investigate the function of Nerfin-1, we used a nerfin-1 ${ }^{159}$-null mutant (Kuzin et al. 2005) to generate loss-of-function MARCM (mosaic analysis with a repressible cell marker) clones (Lee and Luo 2001). Clones were induced at $24 \mathrm{~h} \mathrm{ALH}$ in the larval CNS and dissected $96 \mathrm{~h}$ later. While control clones in the ventral nerve cord (VNC) always contained one large NB positive for the neural progenitor-specific marker Mira (Fig. 2A-A" [white arrow], C), most type I nerfin- $1^{159}$ clones $(88 \% ; n=50)$ contained multiple Mira ${ }^{+}$cells per clone (Fig. 2B-B",C), resulting in an average 2.9-fold increase in total clonal volume (Fig. 2D). We detected no Nerfin-1 protein in nerfin- $1^{159}$ clones (Supplemental Fig. S1C, $C^{\prime}$ ). In addition, Nerfin-1-GFP, a GFP-tagged full-length genomic nerfin-1 construct (Kuzin et al. 2005), was sufficient to rescue the majority of nerfin- $1^{159}$ clones to one NB per clone (Supplemental Fig. S1D,E).

nerfin- $1^{159}$ clones were highly proliferative compared with wild-type clones, as indicated by significant increases in incorporation of the thymidine analog and S-phase marker 5-ethynyl-2'-deoxyuridine (EdU) (Supplemental Fig. S4, cf. $\mathrm{B}, \mathrm{B}^{\prime}$ and $\mathrm{A}, \mathrm{A}^{\prime}$, quantified in E) and cells positively labeled for the mitotic marker $\mathrm{pH} 3$ in nerfin- ${ }^{159}$ in comparison with control clones (Supplemental Fig. S4, cf. $\mathrm{D}, \mathrm{D}^{\prime}$ and $\mathrm{C}, \mathrm{C}^{\prime}$, quantified in F). Control NBs undergo terminal differentiation at $\sim 120 \mathrm{~h} \mathrm{ALH}$ (Maurange et al. 2008; Homem et al. 2014). In contrast, the ectopic nerfin- ${ }^{159}$ Mira $^{+}$cells failed to undergo timely differentiation during pupal life and continued to be highly proliferative during adult stages (indicated by $\mathrm{pH} 3^{+}$and EdU $^{+}$cells compared with control) (Fig. 2E-F"; Supplemental Fig. S4G-H'). The presence of nerfin-1 ${ }^{159}$ tumor masses consisting mostly of undifferentiated Elav ${ }^{-} / \mathrm{Mira}^{+}$ progenitors (Supplemental Fig. S4, cf. J-J" and I-I") shortened animal life span by $40 \%$ (Fig. 2G). These tumors were capable of metastasis when transplanted into the abdomen of naive adult hosts, migrating to distant organs such as the eye (Fig. 2H, arrow).

In type II NB lineages, we observed a similar but less dramatic phenotype. Loss of nerfin-1 did not alter the number of type II NBs (one per clone, Ase ${ }^{-} / \mathrm{Mira}^{+}$) (Supplemental Fig. S5, cf. B-B" and A-A", yellow arrows) but resulted in an expansion of the Ase ${ }^{+}$INPs (Supplemental Fig. S5, cf. D-D" and C-C", quantified in F) and a 1.3-fold increase in overall clonal volume (Supplemental Fig. S5E). The INPs, which normally reside in superficial sections of control clones, are now found in both superficial (Supplemental Fig. S5K-K",M-M") and deep sections of nerfin- $1^{159}$ clones typically occupied by neurons (Supplemental Fig. S5L-L",N-N"); however, we did not detect a corresponding increase in proliferation, as assessed by the number of cells positively labeled by cell cycle markers (Supplemental Fig. S5G [M phase, pH3], $\mathrm{H}$ [S phase, EdU], I,J [CycA and CycE, G1 phase]). To investigate why the ectopic INPs are not proliferative, we used the markers Dpn and Ase to distinguish between mature and immature INPs (Bowman et al. 2008; Weng et al. 2010). Importantly, we found a significant increase in the number of immature nonproliferative Ase $^{+}, \mathrm{Dpn}^{-}$INPs (Supplemental Fig. 5SK-N",Q). As it was previously shown that immature INPs require an average of $6.6 \mathrm{~h}$ to mature before they undergo divisions (Weng et al. 2010; Homem et al. 2013), we assessed nerfin-1 ${ }^{159}$ clone size later in development (120 $\mathrm{h}$ after clone induction) and found that nerfin- $1^{159}$ 


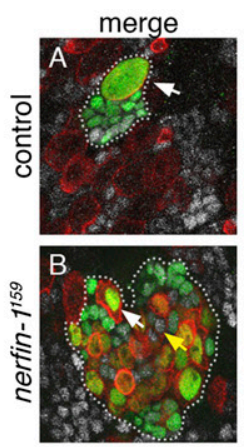

merge
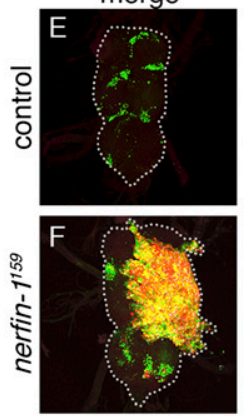

I

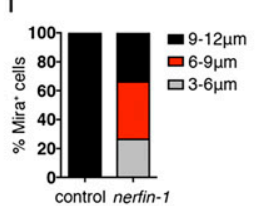

control nerfin-159

NBs large NBs
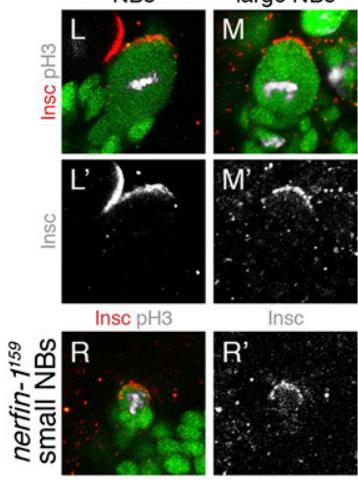

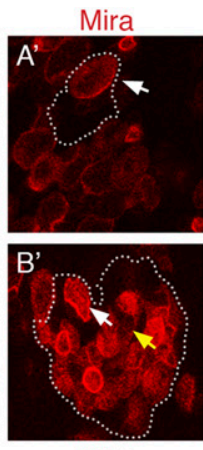

Mira
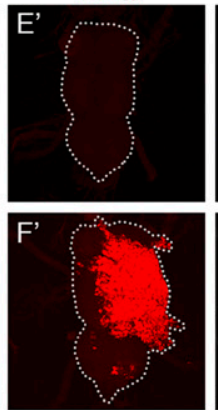

$J$
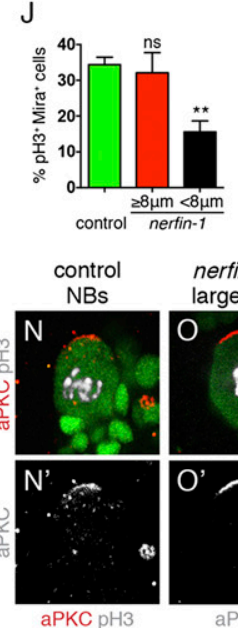

nerfin-159 large NBs

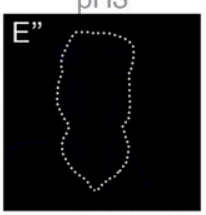

$\mathrm{S}$

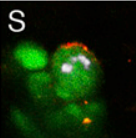

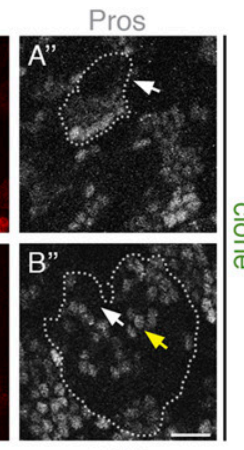

C
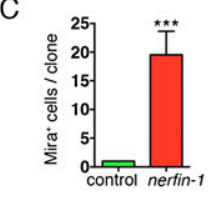

D
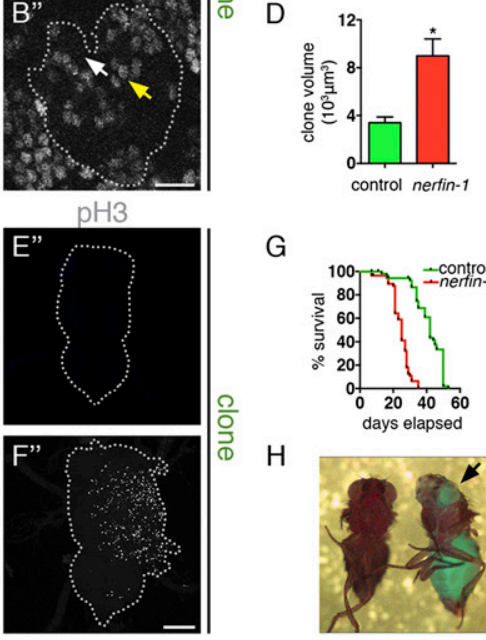

K

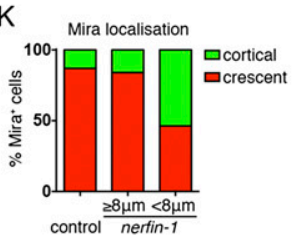

G

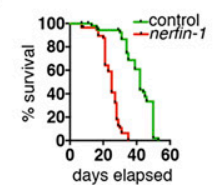

$\mathrm{H}$

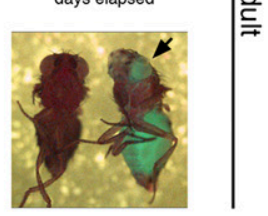

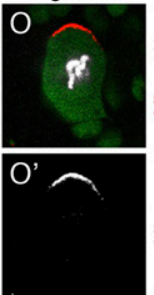

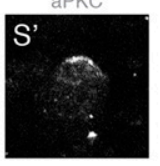

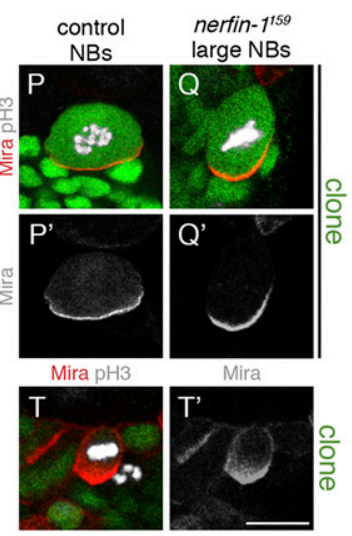

Figure 2. Nerfin-1 inhibits neuroblast overgrowth in the larval and adult CNS. $\left(A-B^{\prime \prime}\right)$ Size comparison of control or nerfin- $1^{159}$ MARCM clones in the larval VNC. Control clones contain one large Mira ${ }^{+} \mathrm{NB}$ (red; white arrow), and nerfin$1^{159}$ clones contain $20 \mathrm{Mira}^{+}$cells on average (quantified in $C ; m=19.55$, SEM $=4.10, n=11$ ) of variable cell sizes. The large Mira ${ }^{+}$cells $\left(B-B^{\prime \prime}\right.$, white arrow) are Pros $^{-}$, and the small $\mathrm{Mira}^{+}$cells $\left(B-B^{\prime \prime}\right.$, yellow arrow) are Pros $^{+}$. The increase in $\mathrm{Mira}^{+}$cell numbers results in a 2.9-fold expansion in clone volume $4 \mathrm{~d}$ after clone induction $\left(D_{\text {; }}\right.$ control: $m=3.38 \times 10^{3} \mu \mathrm{m}^{3}, \mathrm{SEM}=0.49 \times 10^{3}$ $\mu \mathrm{m}^{3}, n=57$; nerfin-1 $1^{159}: m=8.99 \times 10^{3} \mu \mathrm{m}^{3}$, $\left.\mathrm{SEM}=1.41 \times 10^{3} \mu \mathrm{m}^{3}, n=137\right) \cdot\left(E-F^{\prime \prime}\right)$. In contrast to control NBs which are absent in adult MARCM clones $\left(E-E^{\prime \prime}\right)$, nerfin- ${ }^{159}$ mutant Mira ${ }^{+}$cells $\left(F, F^{\prime}\right)$ fail to undergo timely differentiation during pupal life and continue to be highly proliferative during adult stages $\left(F^{\prime \prime}\right.$; indicated by $\mathrm{pH} 3^{+}$, white), resulting in large tumor clones that are detrimental to the adult hosts, shortening their average life span by $40 \%(G$; control: median survival $=42 \mathrm{~d}, n=56$; nerfin- $1^{159}$ : median survival $\left.=25 \mathrm{~d}, n=57\right) .(H)$ Upon transplantation of nerfin- ${ }^{159}$ tumor fragments into the abdomen of naive hosts, nerfin- $1^{159}$ brain cells $\left(\mathrm{GFP}^{+}\right.$, right; $\left.n=10\right)$ but not $\mathrm{GFP}^{+}$ control brain cells (left; $n=10$ ) overgrow and metastasize to distant sites such as the eye (arrow). (I) Histogram depicting NB cell size; $100 \%$ of control NBs $(n=37)$ are between 9 and $12 \mu \mathrm{m}$ in diameter. In nerfin- ${ }^{159}$ clones $(n=82), 26.3 \%$ of $\mathrm{Mira}^{+}$cells are between 3 and $6 \mu \mathrm{m}, 39.7 \%$ are between 6 and $9 \mu \mathrm{m}$, and $44 \%$ are between 9 and $12 \mu \mathrm{m}$. (J) Histogram depicting the percentage of Mira $^{+}$cells in M phase (control: $m=34.4 \%$, SEM = $2.06 \%, n=5$; large nerfin- $1^{159}$ Mira $^{+}$cells $\geq 8 \mu \mathrm{m}$ : $m=32.12 \%, \mathrm{SEM}=5.6 \%, n=10$; small nerfin $-1^{159}$ $\mathrm{Mira}^{+}$cell $<8 \mu \mathrm{m}: m=15.6 \%, \mathrm{SEM}=3.03 \%, n=$ 10). (K) Eighty-seven percent of control NBs $(n=$ 23), $84 \%$ of large nerfin- ${ }^{159} \mathrm{Mira}^{+}$cells $(n=24)$, and $46.2 \%$ of small nerfin- $~^{159}$ Mira $^{+}$cells $(n=24)$ correctly localize basal polarity marker Mira. $\left(L-T^{\prime}\right)$ representative images of apical markers Insc and aPKC and basal marker Mira in large and small NBs at metaphase. $E-F^{\prime \prime}$ are maximum projections. Bars: $A-B^{\prime \prime}, L-T^{\prime}, 10 \mu \mathrm{m} ; E-F^{\prime \prime}, 50 \mu \mathrm{m}$. (ns) $P>0.05$; $\left.{ }^{*}\right) P \leq 0.05 ;\left(^{\star \star}\right) P \leq 0.01 ;\left(^{\star \star \star}\right) P \leq 0.001$. See also Supplemental Figures S4-S7. clones are 1.7-fold larger than control clones (Supplemental Fig. 5SR) as a result of an increase in the number of mature INPs (data not shown). However, unlike type I lineages (Supplemental Fig. S5P, $\mathrm{P}^{\prime}$, white arrows) that contained multiple NBs, nerfin- $1^{159}$ type II neurons (Supplemental Fig. S5P-P", yellow arrows) dedifferentiate to give rise to ectopic INPs but do not fully revert to NBs by $120 \mathrm{~h} \mathrm{ALH}$.

nerfin- ${ }^{159}$ mutant clones contain ectopic Mira $^{+}$cells of variable size

Upon close examination of nerfin- $1^{159}$ type I tumor clones, we found that unlike wild-type NBs, which maintain a constant size of $\sim 9-12 \mu \mathrm{m}$ in diameter throughout neurogenesis (Maurange et al. 2008), nerfin-1 ${ }^{159}$ Mira $^{+}$ cells varied between 3 and $12 \mu \mathrm{m}$ in diameter (Fig. 2I). We then correlated NB size with specific marker expression. Control NBs (Fig. 2A-A") or nerfin- $1^{159}$ Mira $^{+}$cells that were $\geq 8 \mu \mathrm{m}$ in diameter never expressed the neuronal differentiation marker Pros (Fig. 2B-B", white arrow). In contrast, a proportion of the smaller nerfin- $1^{159}$ Mira $^{+}$ cells $(<8 \mu \mathrm{m})$ expressed both NB and neuronal markers $\left(\mathrm{Mira}^{+} / \mathrm{Pros}^{+}\right.$cells) (Fig. 2B-B", yellow arrow). Given that wild-type NBs were never $<8 \mu \mathrm{m}$, we divided nerfin- $1^{159}$ ectopic $\mathrm{Mira}^{+}$cells into two groups: Large $\mathrm{Mira}^{+}$cells, defined to be $\geq 8 \mu \mathrm{m}$, were comparable in size with wildtype NBs, whereas small Mira ${ }^{+}$cells, defined to be $<8 \mu \mathrm{m}$, 
were significantly smaller than wild-type NBs but larger than control neurons (Supplemental Fig. S6A). Staining for atypical protein kinase $\mathrm{C}(\mathrm{aPKC})$, Inscuteable (Insc), and Mira as representative members of asymmetric division polarity complexes during $M$ phase (Homem and Knoblich 2012) revealed no difference in the localization patterns of these proteins between wild-type and nerfin$1^{159}$ large ectopic $\mathrm{Mira}^{+}$cells (Fig. 2, cf. L, $\mathrm{L}^{\prime}$ and $\mathrm{M}, \mathrm{M}^{\prime}$, $\mathrm{N}, \mathrm{N}^{\prime}$ and $\mathrm{O}, \mathrm{O}^{\prime}$, and $\mathrm{P}, \mathrm{P}^{\prime}$ and $\left.\mathrm{Q}, \mathrm{Q}^{\prime}\right)$. However, in around half of the nerfin- $1^{159}$ small ectopic Mira ${ }^{+}$cells, we observed cortical mislocalization of polarity proteins (representative Mira localization is quantified in Fig. $2 \mathrm{~K}$, representative Insc, aPKC, and Mira staining is shown in $\mathrm{R}^{-\mathrm{T}^{\prime}}$; Supplemental Fig. S6B). In addition, $100 \%$ of nerfin- ${ }^{159}$ large $\mathrm{Mira}^{+}$cells underwent asymmetric self-renewal (Supplemental Fig. S7A-B"'; Supplemental Movie S3) at a cell cycle speed comparable with that of control NBs (Fig. 2); Supplemental Fig. S7E-E"'; Supplemental Movies S2, S6; Homem et al. 2013). In contrast, small Mira ${ }^{+}$cells sometimes exhibited cell cycle defects (Fig. 2J) and atypical size-symmetric divisions (Supplemental Fig. S7C-D"'; Supplemental Movies S4, S5). As these nerfin- $1^{159}$ ectopic Mira ${ }^{+}$cells were capable of selfrenewing and giving rise to mature neurons, we concluded that these cells were ectopic NBs.

\section{nerfin- $1^{159}$ ectopic NBs arise by dedifferentiation}

In order to trace the cell of origin of the ectopic NBs, we carried out a time-course experiment to establish the earliest time point at which they first arise in nerfin- $1^{159}$ clones. We found no ectopic NBs $24 \mathrm{~h}$ after clone induction (Fig. 3A-B"). By $48 \mathrm{~h}, \mathrm{Mira}^{+}$cells with size $(\sim 5 \mu \mathrm{m})$ and position characteristics of post-mitotic neurons $(\sim 8 \mu \mathrm{m}$ from the parental NB) were identified in nerfin- ${ }^{159}$ clones $(78 \% ; n=14)$ (Fig. 3C-D"; Supplemental Fig. S8A-D'), indicating that these ectopic NBs were likely dedifferentiated neurons. To test this hypothesis, we fed larvae with $\mathrm{EdU}^{+}$food for $4 \mathrm{~h}$ at $24 \mathrm{~h}$ after clone induction and then chased for $24 \mathrm{~h}$ with EdU-free food (Fig. 3I). In control animals, EdU was first incorporated by the dividing NBs during feeding and inherited by neurons generated during this time window. During EdU-free chase, additional NB divisions gave rise to further neurons, thus displacing EdU-labeled cells into deeper locations within the CNS $(\sim 7.5 \mu \mathrm{m}$ from the parental NB) (Fig. 3I-K"). Strikingly, $48 \mathrm{~h}$ after clone induction (the earliest time point at which ectopic NBs were first identified), we observed $\mathrm{Mira}^{+}$cells in the deep sections of nerfin- $1^{159}$ clones that were also EdU ${ }^{+}$, indicating that they were in fact NBs newly derived from differentiated neurons (Fig. 3, cf. L-M", yellow arrow, and J-K"). Between 48 and $72 \mathrm{~h}$ after clone induction, the rate of neuron-toNB reversion rapidly increased (Fig. 3E-F", G; Supplemental Fig. S8E- $\mathrm{H}^{\prime \prime}$ ), accompanied by an enlargement in average NB cell size (Fig. $3 \mathrm{H}$ ) and enhanced cell cycle speed (Supplemental Fig. S8I). To further support the model that nerfin- $1^{159}$ ectopic NBs are derived from neurons, we carried out live-cell imaging of dissociated type I NB clones (Supplemental Fig. S9H-I"; Supplemental
Movies S7, S8). While control neurons did not significantly increase their cellular volume or undergo divisions during the $11 \mathrm{~h}$ of live imaging (Supplemental Fig. S9H-H", J), nerfin- $1^{159}$ cells $<7 \mu \mathrm{m}$ (Fig. 2I; typical of small ectopic NBs or neurons and significantly smaller than wild-type NBs, as quantified in Supplemental Fig. S6A) increased their cellular volume by an average of 5.3-fold and underwent asymmetric cell divisions (Supplemental Fig. S9I$\left.\mathrm{I}^{\prime \prime}, \mathrm{J}\right)$. Finally, to investigate whether Nerfin-1 is continuously required for neuronal maintenance, we induced nerfin-1 ${ }^{159}$ clones later in development, at 48 and $72 \mathrm{~h} \mathrm{ALH}$. We found that Nerfin-1 is indeed required to maintain neuronal differentiation throughout larval neurogenesis, as ectopic NBs arose upon removal of Nerfin-1 at both early (24 h ALH) (Fig. 3) and late time points (Supplemental Fig. S9A-F'). Together, these analyses indicate that both the small and large NB populations were derived from post-mitotic neurons and that these newly dedifferentiated cells undergo rapid growth to give rise to fastproliferating large NBs, thus contributing to aggressive tumor growth.

Myc- and Tor-mediated cellular growth regulates neuron-to-NB reversion in nerfin- ${ }^{159}$ clones

The increase in the size of ectopic NBs over time (Fig. 3H; Supplemental Fig. S9H-J; Supplemental Movies S7, S8) and the fact that nerfin- $1^{159}$ neurons were significantly larger than control neurons (Supplemental Fig. S6A) suggested that cell growth-dependent mechanisms might facilitate the neuron-to-NB reversions in nerfin- $1^{159}$ clones. To test this hypothesis, we first examined the ratio of nucleolar to nuclear volume, which is an indicator of ribosomal biogenesis and cellular growth in both NBs and neurons (Fig. 4A-C', nucleolus is marked with fibrillarin [Fib]). Strikingly, we found that this ratio was significantly increased in not only nerfin- $1^{159}$ NBs (Fig. $4 \mathrm{~B}, \mathrm{~B}^{\prime}$, marked by $\mathrm{Dpn}^{+}$, quantified in $\mathrm{D}$, cf. with control NBs, A, $\mathrm{A}^{\prime}$, white arrows) but also nerfin-159 $\mathrm{Dpn}^{-}$neurons (Fig. 4C, $\mathrm{C}^{\prime}$, quantified in $\mathrm{D}$, cf. with control neurons, $\mathrm{A}, \mathrm{A}^{\prime}$, yellow arrows), suggesting that cellular growth precedes the neuron-to-NB reversion. In addition, we found that $\mathrm{Myc}$, a global regulator of ribosome biogenesis (de la Cova and Johnston 2006) was not only expressed in $\mathrm{Mira}^{+} \mathrm{NBs}$ (Fig. 4F-F", yellow arrow) but now up-regulated in $\mathrm{Mira}^{-} / \mathrm{Elav}^{+}$neurons (Fig. 4H-H", yellow arrow) in nerfin- $1^{159}$ clones compared with control clones (Fig. 4E-E",G-G", yellow arrow). To test whether Myc is required for nerfin- $1^{159}$ clonal growth, we knocked it down with RNAi (specificity verified in Supplemental Fig. $\mathrm{S} 10 \mathrm{~B}, \mathrm{~B}^{\prime}$ ) and found that it was sufficient to reduce nerfin- $1^{159}$ clonal volume by $50 \%$ (Fig. $4 \mathrm{I}, \mathrm{J}$, quantified in $\mathrm{K})$. Since Myc is implicated in cell cycle progression (Johnston et al. 1999), we next examined whether its knockdown decreased clonal growth via inhibition of the cell cycle. Interestingly, inhibition of Myc did not alter the cell cycle speed of nerfin- $1^{159}$ mutant NBs (Supplemental Fig. S10A). On the other hand, Myc knockdown did cause a reduction in the number of both large and small NBs in nerfin- $1^{159}$ clones (Fig. 4L), 

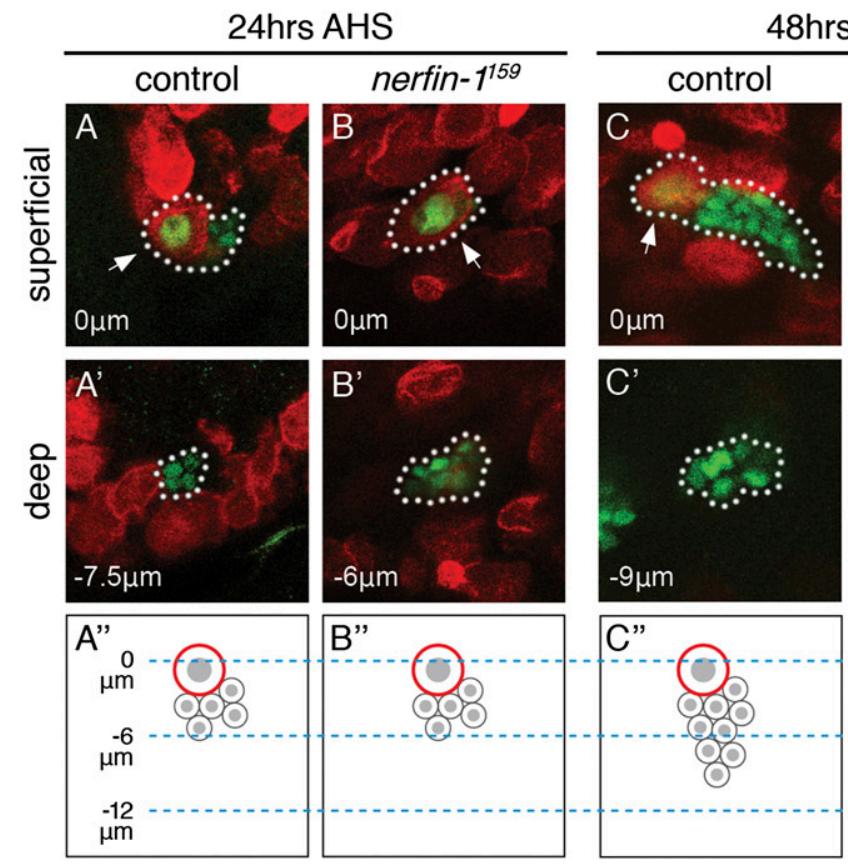

4hrs AHS
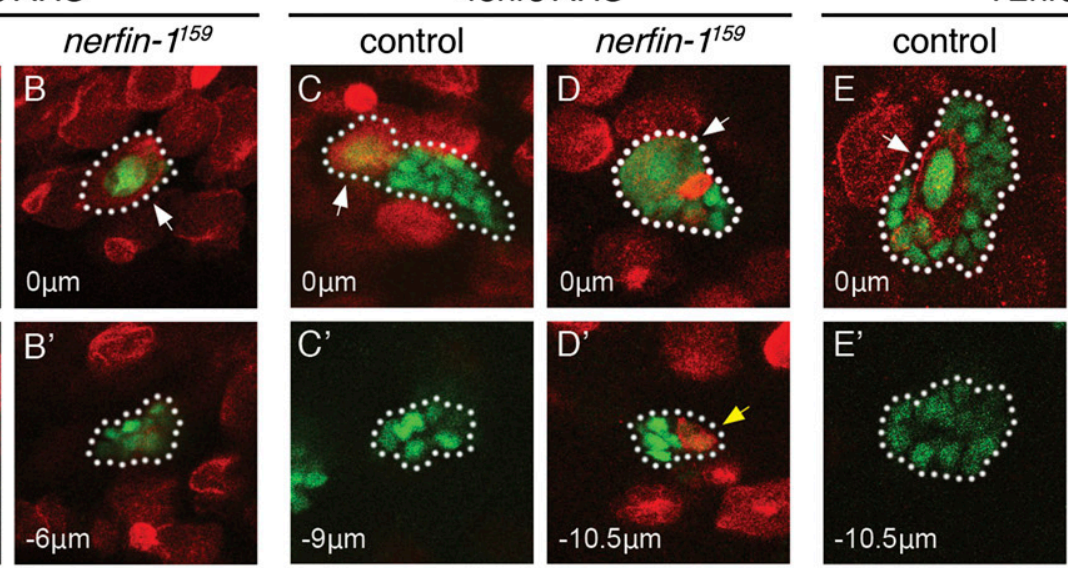

72hrs AHS
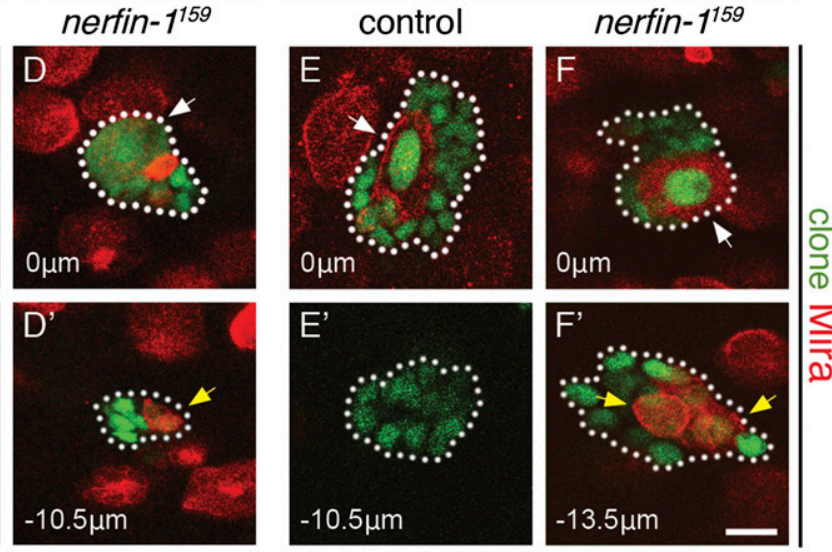

C"
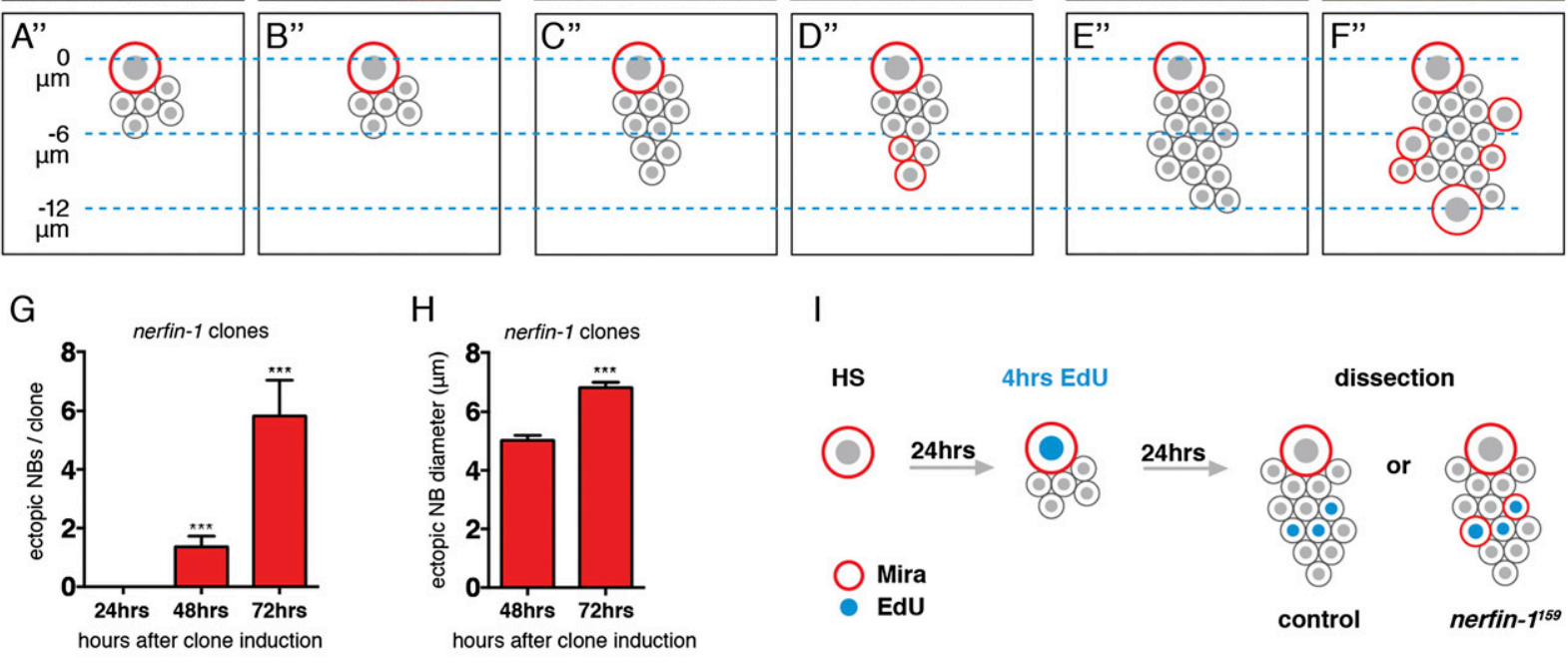

I

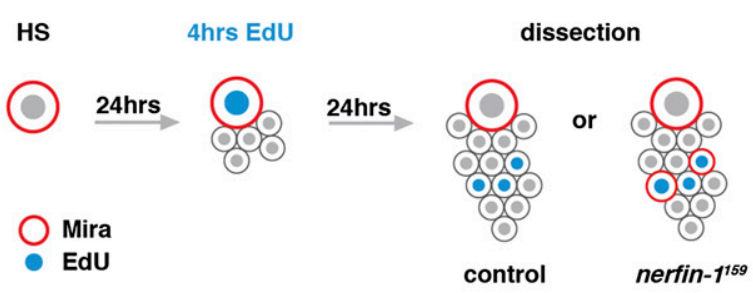

control
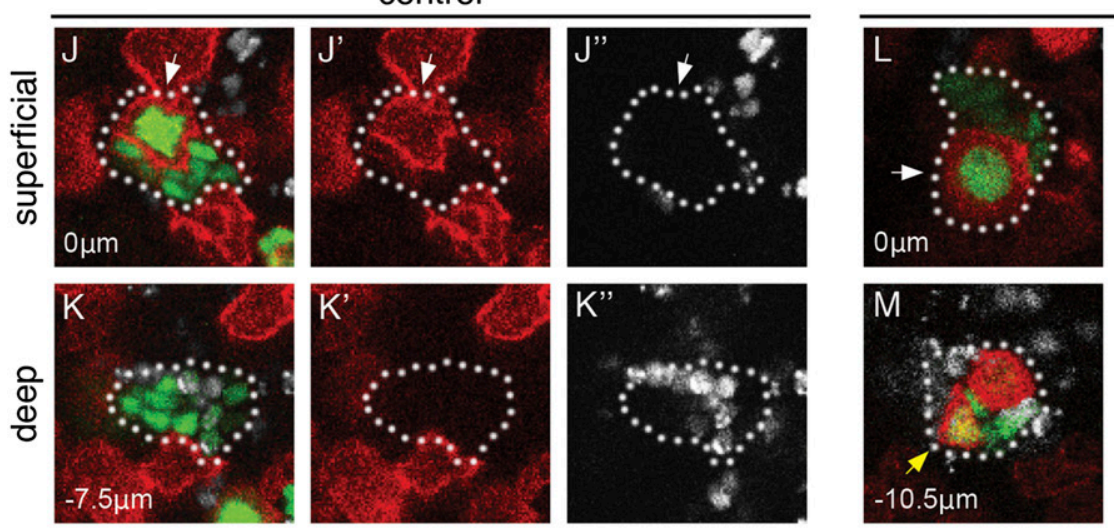

nerfin-1159
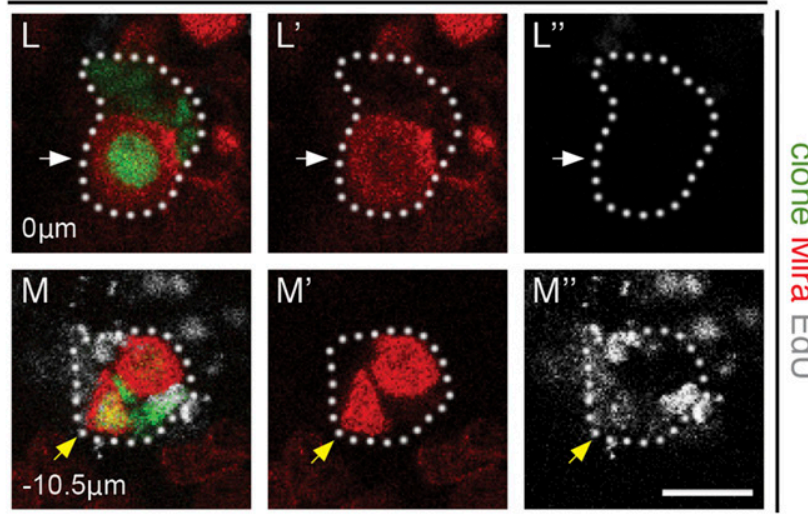

Figure 3. nerfin- $1^{159}$ ectopic NBs arise from dedifferentiation of neurons. $\left(A-F^{\prime \prime}\right)$ Control and nerfin- $1^{159}$ clones were examined at $24 \mathrm{~h}$ $\left(A-B^{\prime}\right), 48 \mathrm{~h}\left(C-D^{\prime}\right)$, and $72 \mathrm{~h}\left(E-F^{\prime}\right)$ after clone induction and stained with the NB marker Mira (red). The parental NBs, identified by their large size and location in superficial sections of the brain $(0 \mu \mathrm{m})$, are marked with white arrows, and ectopic Mira ${ }^{+}$cells are marked with yellow arrows. $\left(A^{\prime \prime}, B^{\prime \prime}, C^{\prime \prime}, D^{\prime \prime}, E^{\prime \prime}, F^{\prime \prime}\right)$ The results are summarized in the schematics. $\left(A-B^{\prime \prime}\right)$ No ectopic NBs were identified in nerfin- $1^{159}$ and control clones at $24 \mathrm{~h}$ after clone induction. $\left(C-F^{\prime \prime}\right)$ Ectopic NBs were detected in nerfin- $1^{159}$ clones at 48 and $72 \mathrm{~h}$ after clone induction in the deepest sections of the clones. $(G)$ Histogram depicting the frequency of ectopic NBs at 24,48 , and $72 \mathrm{~h}$ after clone induction in nerfin- $1^{159}$ clones ( $24 \mathrm{~h}: m=0, \mathrm{SEM}=0, n=22 ; 48 \mathrm{~h}: m=1.36, \mathrm{SEM}=0.36, n=25 ; 72 \mathrm{~h}: m=5.83, \mathrm{SEM}=1.23, n=23$ ). $(H)$ Histogram depicting the average ectopic NB diameter at 48 and $72 \mathrm{~h}$ after clone induction in nerfin- $1^{159}$ clones $(48 \mathrm{~h}: \mathrm{m}=5.03$, SEM $=0.17, n=24 ; 72 \mathrm{~h}: m=6.82, \mathrm{SEM}=0.19, n=129)$. (I) Schematic depicting the EdU pulse-chase experiment in control and nerfin- $1^{159}$ clones. Animals were fed EdU-containing food for $4 \mathrm{~h}$ at $24 \mathrm{~h}$ after clone induction and then chased with EdU-free food for $24 \mathrm{~h} .\left(J-K^{\prime \prime}\right)$ In control clones, no $\mathrm{EdU}^{+} / \mathrm{Mira}^{+}$cells were recovered $(0 \% ; n=18)$. $\left(L-M^{\prime \prime}\right)$ In nerfin- $1^{159}$ clones, EdU ${ }^{+} / \mathrm{Mira}^{+}$ectopic NBs located in deep sections normally occupied by post-mitotic neurons were recovered in $33 \%$ of the clones $(n=18$; yellow arrow). (J-L") Parental NBs are marked with white arrows. Bars, $10 \mu \mathrm{m} .\left(^{\star \star \star}\right) P \leq 0.001$. See also Supplemental Figures S8-S10. 

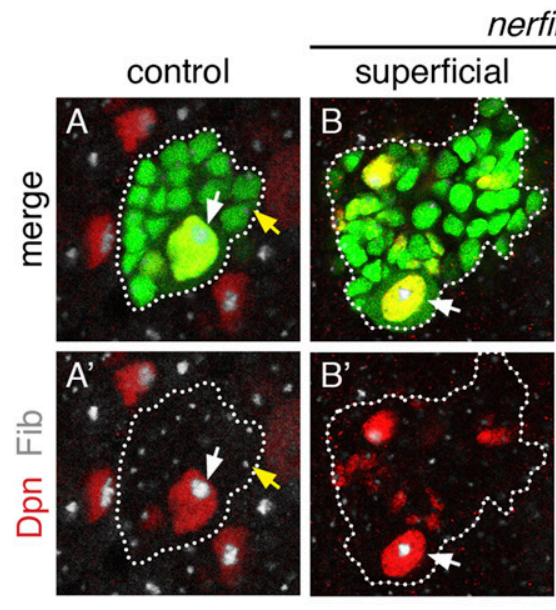

erfin-1159
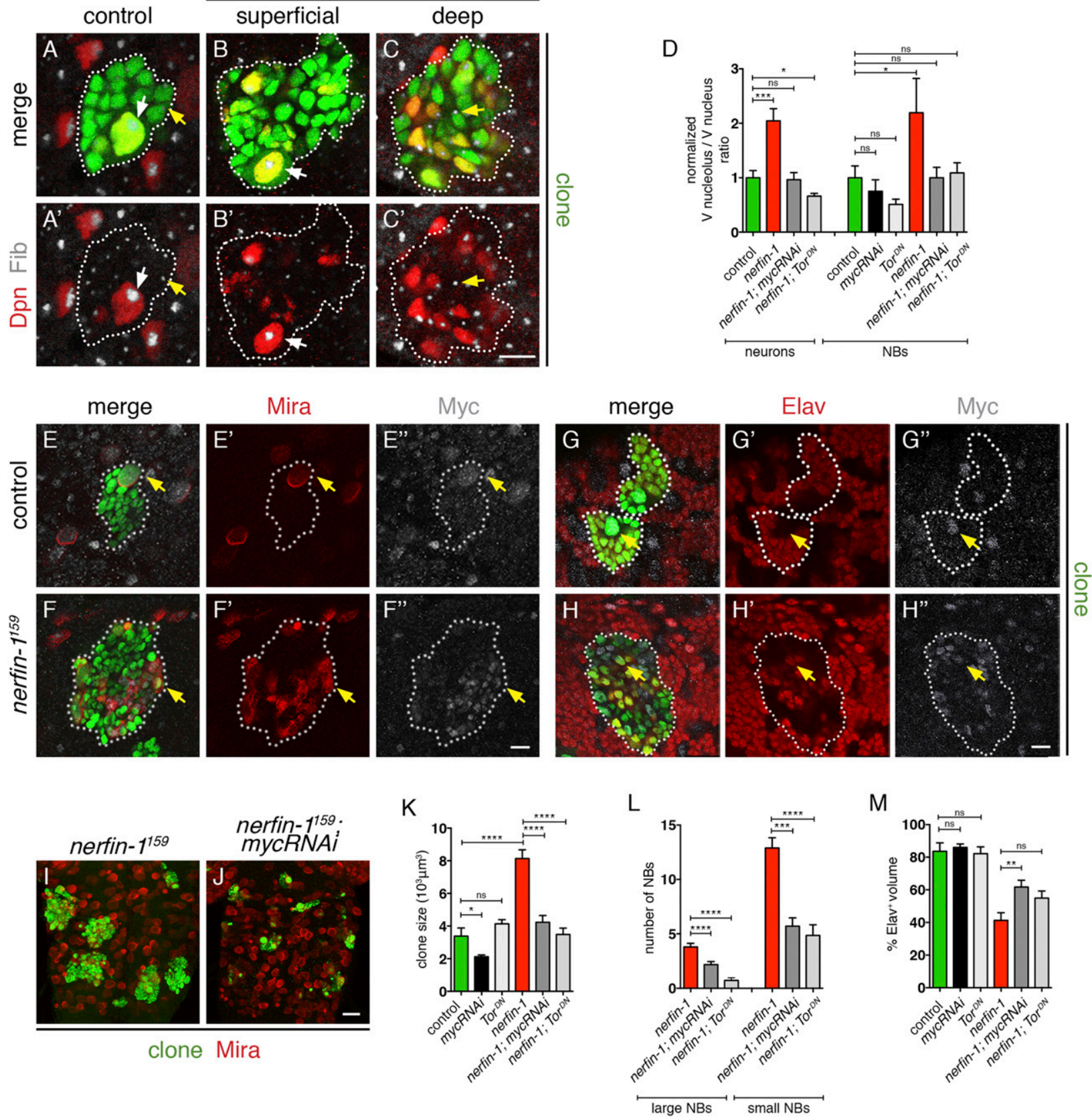

Figure 4. Myc- and Tor- mediated cellular growth regulate neuron-to-NB reversion in nerfin- $1^{159}$ clones. $\left(A-C^{\prime}\right)$ The ratio of nucleolus (marked by Fib, white) to nuclear (marked by nGFP, green) volume is significantly increased in nerfin- $1^{159} \mathrm{NBs}\left(\mathrm{Dpn}^{+}\right.$, red; white arrow) and neurons (Dpn ${ }^{-}$, yellow arrow), as quantified in $D$ (control NBs: $m=1.89, \mathrm{SEM}=0.47, n=14$; nerfin- $1^{159} \mathrm{NBs:} m=3.55, \mathrm{SEM}=0.45, n=20$; control neurons: $m=1.01$, SEM $=0.13, n=22$; nerfin- $1^{159}$ neurons: $\left.m=2.08, \mathrm{SEM}=0.22, n=27\right)$. Myc and Tor inhibition does not alter the nucleolus to nuclear volume ratio (mycRNAi: $m=1.68, \mathrm{SEM}=0.47, n=9$; $\operatorname{Tor}^{D N}: m=1.14, \mathrm{SEM}=0.21, n=9$ ) but is sufficient to restore nerfin- $1^{159}$ nucleolus to nuclear volume ratio to control levels in both nerfin- $1^{159}$ neurons and NBs $\left(D ;\right.$ nerfin- $1^{159} ;$ mycRNAi neuronal ratio: $m=0.97, \mathrm{SEM}=0.13, n=10$; nerfin- ${ }^{159} ;$ mycRNAi NB ratio: $m=2.24, \mathrm{SEM}=0.42, n=24$; nerfin- $1^{159}$; Tor ${ }^{D N}$ neuronal ratio: $m=0.67$, $\mathrm{SEM}=0.05, n=26$; nerfin- ${ }^{159} ; \operatorname{Tor}^{D N} \mathrm{NB}$ ratio: $\left.m=1.78, \mathrm{SEM}=0.3, n=20\right)$. $\left(E-H^{\prime \prime}\right)$ Myc expression (white) is up-regulated in control Mira ${ }^{+}$ (red) NBs $\left(E-E^{\prime \prime}\right.$, yellow arrow; $G-G^{\prime \prime}$, yellow arrow) and both nerfin- ${ }^{159} \mathrm{Mira}^{+} \mathrm{NBs}\left(F-F^{\prime \prime}\right.$, yellow arrow), and Mira ${ }^{-}$, Elav ${ }^{+}(\mathrm{red})$ neurons $\left(H-H^{\prime \prime}\right.$, yellow arrow). $(I, J)$ RNAi knockdown of myc significantly reduces nerfin- $1^{159}$ tumor growth. $(K)$ Histogram depicting clonal volume under Myc and Tor manipulations (control: $m=3387 \times 10^{3} \mu \mathrm{m}^{3}, \mathrm{SEM}=496 \times 10^{3} \mu \mathrm{m}^{3}, n=57 ;$ mycRNAi: $m=2120 \times 10^{3} \mu \mathrm{m}^{3}, \mathrm{SEM}=$

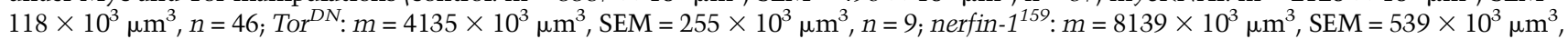

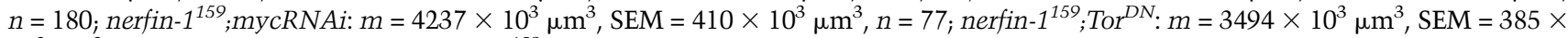
$\left.10^{3} \mu \mathrm{m}^{3}, n=63\right)$. (L) The decrease in nerfin-1 ${ }^{159}$ tumors under Myc and Tor manipulations is due to a reduction in both the number of large $(\geq 8 \mu \mathrm{m})$ and small $(<8 \mu \mathrm{m})$ NBs (nerfin- $1^{159}$ large NBs: $m=4.3, \mathrm{SEM}=0.44, n=23$; nerfin- ${ }^{159} ;$ mycRNAi large NBs: $m=2.17$, SEM $=0.28$, $n=39$; nerfin- ${ }^{159} ;$ Tor $^{D N}$ large NBs: $m=0.72$, SEM $=0.23, n=18$; nerfin- ${ }^{159}$ small NBs: $m=12.9, \mathrm{SEM}=0.90, n=40 ;$ nerfin- $1^{159} ;$ mycRNAi $^{15}$

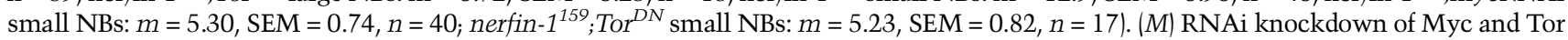
was sufficient to increase the level of differentiation in nerfin $-^{159}$ clones (control: $m=83.63 \%, \mathrm{SEM}=5.18, n=3 ; m y c R N A i: m=86 \%$, $\mathrm{SEM}=2, n=15 ; \operatorname{Tor}^{D N}: m=82.18 \%, \mathrm{SEM}=4.17, n=6 ;$ nerfin $^{159}: \mathrm{m}=41.34 \%, \mathrm{SEM}=4.66, n=21 ;$ nerfin- $1^{159} ;$ mycRNAi: $m=61.67 \%$, $\mathrm{SEM}=4.28, n=15$; nerfin $\left.-1^{159} ; \operatorname{Tor}^{D N}: m=55 \%, \mathrm{SEM}=4.29, n=11\right)$. Bars: $A-C^{\prime}, E-H^{\prime}, 10 \mu \mathrm{m} ; I, J, 25 \mu \mathrm{m} .(\mathrm{ns}) P>0.05 ;\left(^{\star}\right) P \leq 0.05 ;\left(^{\star \star}\right) P \leq$ $\left.0.01 ;\left(^{\star \star \star}\right) P \leq 0.001 ;{ }^{\star \star \star \star}\right) P \leq 0.0001$. See also Supplemental Figures S10-S11. 
suggesting that it affected both neuron-to-NB reversion (accounting for the decrease in small NBs) and NB cellular growth (which resulted in the reduction in large NB numbers). Consistent with this model, Myc knockdown was sufficient to restore the nerfin- $1^{159}$ nucleolar/ nuclear volume ratio to wild-type level in both NBs and neurons (Fig. 4D). Consequently, many more neurons remained differentiated, as indicated by the percentage of Elav-positive cells per clone (Fig. 4M). Similarly, we found that slowing down cellular growth via expressing a dominant-negative form of Tor $\left(\operatorname{Tor}^{D N}\right)$ (Hennig and Neufeld 2002) also reduced the nucleolar/nuclear volume ratio (Fig. 4D) in nerfin- $1^{159}$ clones. Similar to Myc knockdown, this resulted in the reduction in NB numbers (Fig. 4L), enhanced differentiation (Fig. 4M), and decreased tumor volume (Fig. 4K) independent of cell cycle progression (Supplemental Fig. S10A). We found that the Tor-dependent effects were administered by the TORC1 complex, as the Rag complex, which activates TORC1 in response to amino acids (Kim et al. 2008), and the TORC1 component Raptor (Lee and Chung 2007) were both required for nerfin- $1^{159}$ clonal growth (Supplemental Fig. S11). Together, these results indicate that Myc- and Tor-dependent mechanisms are required for nerfin- $1^{159}$ tumor growth by regulating both the rate of neuron-to-NB reversion and the increase in cellular volume.

\section{Self-renewal and neuronal differentiation are commonly deregulated in nerfin- $1^{159}$ and $\operatorname{pros}^{17}$ tumors}

The homeodomain transcription factor Pros was previously shown to promote neuronal differentiation (Bello et al. 2006; Betschinger et al. 2006; Choksi et al. 2006). In $\operatorname{pros}^{17}$ clones, GMCs failed to give rise to neurons, resulting in tumor clones consisting almost exclusively of NBs (Fig. 5B-C'"). To compare the transcriptional networks required for neuronal maintenance administered by Nerfin-1 versus neuronal differentiation promoted by Pros, we conducted a genome-wide transcriptional profile analysis of nerfin- $1^{159}$ and pros $^{17}$ mutant clones. GFP-labeled mutant or control cells were isolated through fluorescence-activated cell sorting (FACS) as described in Berger et al. (2012). Total RNA was extracted, sequenced (see the Materials and Methods), and compared with control to identify differentially expressed genes. We found a strong correlation between genes that were deregulated in both nerfin- $1^{159}$ and $\operatorname{pros}^{17}$ clones (Supplemental Figs. S12A-D, S13), with $82 \%$ overlap between up-regulated genes in nerfin- ${ }^{159}$ and pros $^{17}$. However, fewer genes were commonly down-regulated in nerfin- $1^{159}$ and pros $^{17}$ clones, with only $44 \%$ overlap. We compared our list of differentially expressed genes with NB- and neuronal-specific genes previously identified through transcriptional profiling of FACS-sorted NBs
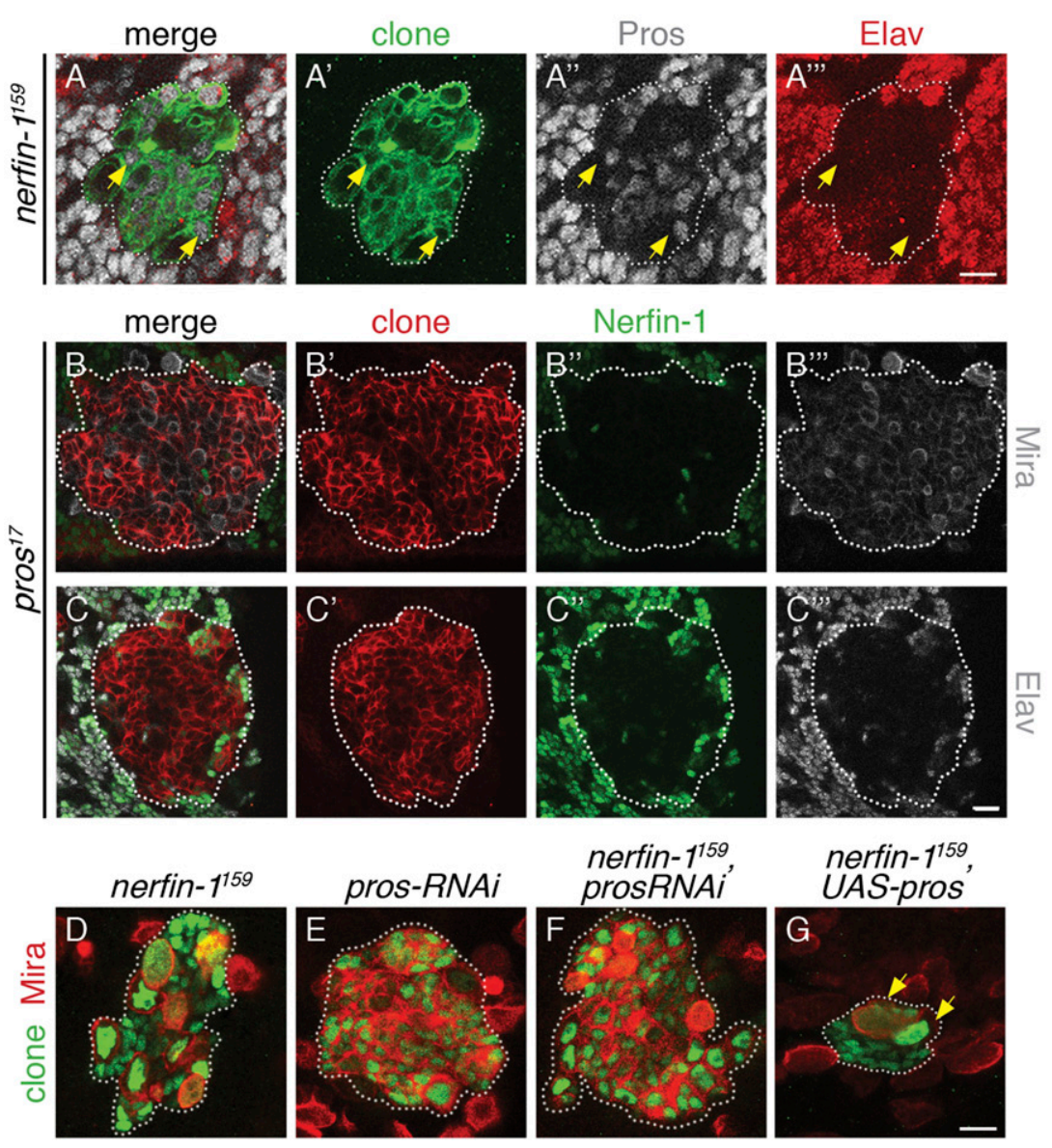

nerfin- 1159 prosRNAi'

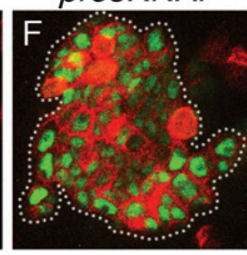

nerfin- $1^{159}$
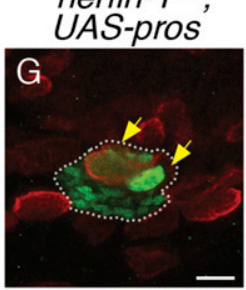

Figure 5. Pros and Nerfin-1 act sequentially to promote neuronal specification. $\left(A-A^{\prime \prime \prime}\right)$ Elav expression (red) is down-regulated in more cells than Pros expression (white) in nerfin- $1^{159}$ clones (green). $\left(B-C^{\prime \prime \prime}\right)$ Nerfin-1 (green, $B^{\prime \prime}, C^{\prime \prime}$ ) is absent in RFP-labeled $\operatorname{pros}^{17}$ clones (red) that consist mostly of NBs $\left(\mathrm{Mira}^{+}\right.$; $B^{\prime \prime \prime}$, white) and are almost completely devoid of differentiated cells $\left(\mathrm{Elav}^{+} ; C^{\prime \prime \prime}\right.$, white). ( $D-$ G) nerfin-1 ${ }^{159}$; prosRNAi $(F)$ phenocopies the prosRNAi $(E)$ clonal phenotype. Overexpression of Pros partially rescues nerfin- $1^{159}$ clones (cf. $G$ and $D$ ) containing zero, one (not shown) or two (G, yellow arrows) NBs per clone. Bars, $10 \mu \mathrm{m}$. See also Supplemental Figures S12-S15. 
and neurons (Berger et al. 2012) and found that 25 NB genes were up-regulated and 64 neuronal genes were downregulated in both pros $^{17}$ and nerfin- $1^{159}$ mutant clones (data not shown). We validated a selected group of these differentially expressed genes by quantitative PCR (qPCR), confirming the up-regulation of the NB-specific genes mira and ase and down-regulation of the neuronal gene elav in both mutant tissues (Supplemental Fig. S14). In addition, immunostaining also confirmed the up-regulation of Ase and Dpn in nerfin- ${ }^{159}$ type I (Supplemental Fig. S12F-G") and type II (Supplemental Fig. S5M-N",Q) clones. Interestingly, $\mathrm{Dpn}^{+}, \mathrm{Mira}^{-}$cells were observed in nerfin- $1^{159}$ mutant clones, suggesting that Dpn derepression precedes the onset of Mira expression in the process of dedifferentiation (Supplemental Fig. S12G-G", yellow arrow). Furthermore, we found up-regulation of the GMC-specific gene target of pox-n (tap) (Bush et al. 1996) and NBspecific gene zipper (zip) in nerfin- $1^{159}$ mutant cells. tap encodes a homolog of the mammalian protein NeuroD, which has been previously shown to be a target of the Nerfin-1 mammalian homolog INSM1 (Liu et al. 2006). Conversely, we found that the neuronal genes Sox21b, scarecrow (scro), and couch potato (cpo) (Kuzin et al. 2005; Southall et al. 2014) were down-regulated in both pros $^{17}$ and nerfin- ${ }^{159}$ clones. Together, these results suggest that Nerfin-1 and Pros regulate similar sets of genes, enabling them to inhibit self-renewal and promote differentiation.

\section{Nerfin-1 regulates NB self-renewal and neuronal differentiation genes}

In order to test whether Nerfin-1 directly regulates the expression of NB and neuronal genes, we carried out a ChIP assay. We were able to show that Nerfin-1 was located in the promoter regions of the self-renewal genes $d p n$ and ase (also targets of Pros) (Choksi et al. 2006) but not that of mira and pros (Supplemental Fig. S12E). Furthermore, we found Nerfin-1 in the proximity of the promoters of neuronal genes sox21b, cpo, and tap (Supplemental Fig. S12E). A fourfold enrichment of Nerfin-1 on the promoter of myc was also detected (Supplemental Fig. S12E), consistent with our finding that the repression of Myc-mediated cellular growth is required to block neuron-to-NB reversion (Fig. 4). Together with our genome-wide differential expression analysis, these results suggest that Nerfin-1 maintains the differentiated state of post-mitotic neurons through direct repression of NB-specific genes and activation of neuronal genes.

Pros and Nerfin-1 act sequentially to promote neuronal specification

Many self-renewal and differentiation genes were commonly deregulated in nerfin-1 and pros mutants; several of them were also direct targets of both Nerfin1 and Pros. However, loss-of-function phenotypes of nerfin-1 and pros mutants are strikingly different. In $\operatorname{pros}^{17}$ and prosRNAi clones, GMCs reverted to NBs at the expense of neuronal generation, resulting in large clones consisting almost entirely of NBs, devoid of
Nerfin-1 protein and mRNA (Fig. 5B-C"',E; Supplemental Fig. S14). nerfin- $1^{159}$ mutant clones, on the other hand, contained a mixture of NBs and neurons (Figs. 2B-B", 4F-F", $\mathrm{H}-\mathrm{H}^{\prime \prime}, 5 \mathrm{~A}-\mathrm{A}^{\prime \prime \prime}, \mathrm{D}$ ) resulting from failure to maintain neuronal differentiation. Consistent with this, Pros expression was reduced only in later stages of neuron-to-NB reversion in nerfin- $1^{159}$ cells (Fig. $5 \mathrm{~A}-\mathrm{A}^{\prime \prime}$, Elav $^{-} /$Pros $^{+}$cells, yellow arrows). These data led us to propose that Pros is required in the GMCs to promote neuronal specification prior to the requirement of Nerfin-1 in the neurons for their maintenance. To test this hypothesis, we performed an epistasis analysis between nerfin-1 and pros mutants. We found that the loss of Pros was epistatic to the loss of Nerfin-1 such that the nerfin- $1^{159}$; prosRNAi phenotype was identical to that of prosRNAi alone (Fig. 5E,F; quantified in Supplemental Fig. S15C), supporting our model that Pros is required in the GMCs at an earlier stage of neurogenesis. Furthermore, Pros overexpression partially rescued the nerfin- $1^{159}$ phenotype (Fig. 5G, some clones still contained multiple NBs, yellow arrows; Supplemental Fig. S15A-B', clone volume quantified in C), indicating that Pros overexpression can promote the differentiation of nerfin- $1^{159}$ ectopic NBs.

Nerfin-1 is required for timely NB differentiation, and ectopic Nerfin-1 promotes differentiation

NBs remain proliferative until $120 \mathrm{~h} \mathrm{ALH}$, where the terminal division of most type I NBs is correlated with the nuclear accumulation of Pros that induces cell cycle exit (Maurange et al. 2008). As our results so far showed that Nerfin-1 activates differentiation-specific genes in post-mitotic neurons, we next examined whether it also plays a role in initiating NB terminal differentiation. We found that Nerfin-1 and Pros colocalized in the nucleus of $29 \%$ of the $\mathrm{Mira}^{+} \mathrm{NBs}$ examined (Fig. 6A-A"; Supplemental Fig. S16), suggesting that Nerfin-1 might also play a role in promoting terminal division. Furthermore, in $24 \%$ of NBs, Nerfin-1 was detected in the absence of Pros (Fig. 6B$\mathrm{B}^{\prime \prime}$, quantified in C; Supplemental Fig. S16), suggesting that Nerfin-1 may be activated in the NBs earlier than Pros at the end of neurogenesis. In addition, Nerfin-1 is also required for terminal differentiation at the end of neurogenesis, as nerfin- $1^{159}$ mutant NBs do not undergo Pros-dependent cell cycle exit (Fig. 6D, $\left.\mathrm{D}^{\prime}\right)$ and remain proliferative during adult stages (Fig. $2 \mathrm{~F}-\mathrm{F}^{\prime \prime}$ ). To test whether ectopic Nerfin-1 can promote differentiation, we expressed a nerfin-1 transgene using the panNB driver dnab-Gal4. Strikingly, we detected a gradual loss of $\mathrm{NBs}$ in the $\mathrm{VNC}$; at $96 \mathrm{~h} \mathrm{ALH}$, we observed a $33 \%$ reduction in NBs numbers (Fig. 6E,F, quantified in M). At $110 \mathrm{~h}$ ALH (10 h before terminal neurogenic divisions), a $53 \%$ reduction in NB numbers was found (Fig. 6G,H, quantified in $\mathrm{M}$ ). The disappearance of NBs was not due to an increase in cell death (data not shown) but was accounted for by an increase in premature differentiation. While larval NBs regrow to their original size after each division, terminally 


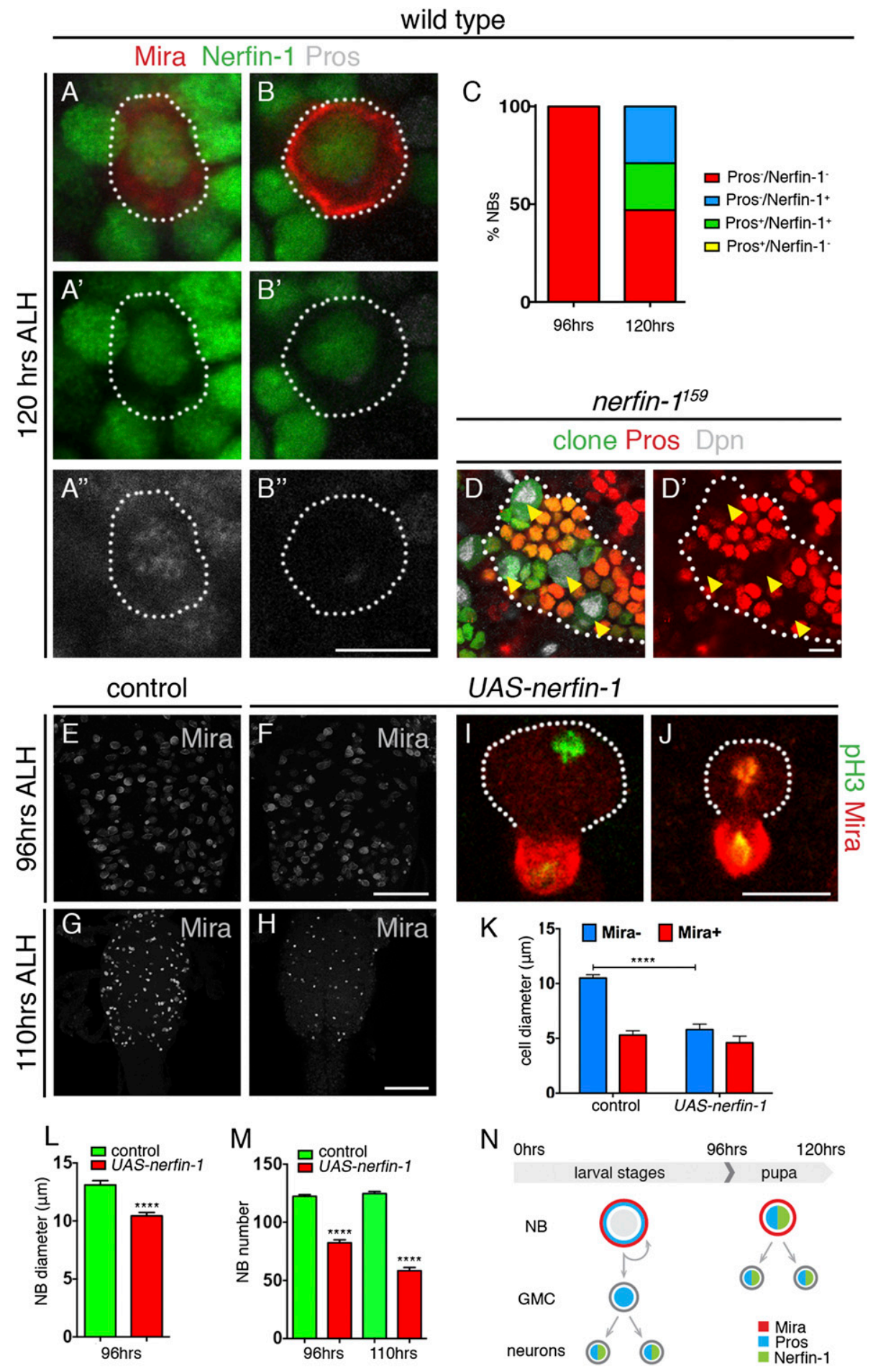

Figure 6. Nerfin-1 is required for timely NB differentiation, and ectopic nerfin-1 promotes differentiation. $\left(A-B^{\prime \prime}\right)$ At the end of neurogenesis (120 h ALH), Nerfin-1 and Pros are localized to the NB ( $\mathrm{Mira}^{+}$, red) nucleus, prior to NB terminal differentiation. In $24 \%$ of NBs, both Pros (white) and Nerfin-1 (green) are expressed in the nucleus $\left(A-A^{\prime \prime}\right)$, and $29 \%$ of NBs express only Nerfin-1 but not Pros $\left(B-B^{\prime \prime}\right)$. $(C)$ Histogram depicting the percentage of nuclear localization of Pros and Nerfin-1 in the NBs at $96 \mathrm{~h}(n=20)$ and $120 \mathrm{~h}(n=17)$. $\left(D-D^{\prime}\right)$ nerfin- $1^{159} \mathrm{NBs}$ $\left(\mathrm{Dpn}^{+}\right.$, white; yellow arrowheads) fail to undergo timely terminal differentiation at $120 \mathrm{~h}$. In these NBs, nuclear Pros (red) localization does not occur. $(E-M)$ Nerfin-1 overexpression in NBs with pan-NB driver dnab-Gal4 induces premature differentiation and reduction in the overall NB numbers at $96 \mathrm{~h}(E, F)$ and $110 \mathrm{~h}(G, H$; maximum projections), as quantified in $M$ (96 h, control: $m=122, \mathrm{SEM}=1.45, n=3$; dnab>nerfin-1: $m=82.4, \mathrm{SEM}=2.49, n=10 ; 110 \mathrm{~h}$, control: $m=125, \mathrm{SEM}=1.8, n=3$; dnab>nerfin-1: $m=58, \mathrm{SEM}=2.6, n=5) .(I, I)$ This reduction in NB numbers corresponds with a reduction in NB diameter, as quantified in $L$ (control: $m=13.1 \mu \mathrm{m}, \mathrm{SEM}=0.36 \mu \mathrm{m}, n=27$; dnab>nerfin-1: $m=10.4 \mu \mathrm{m}, \mathrm{SEM}=0.3 \mu \mathrm{m}, n=24)$, and increase in the incidence of size-symmetric divisions indicative of premature differentiation. $(K)$ Histogram depicting the average diameter of thoracic NBs (Mira $\left.{ }^{-}\right)$and their progeny $\left(\mathrm{Mira}^{+}\right)$during telophase $(\mathrm{control}$, Mira $^{-}: m=10.5 \mu \mathrm{m}, \mathrm{SEM}=0.3 \mu \mathrm{m}, n=10 ; \mathrm{Mira}^{+}: m=5.3 \mu \mathrm{m}, \mathrm{SEM}=0.4 \mu \mathrm{m}, n=10 ;$ dnab $>$ nerfin-1, Mira ${ }^{-}: m=5.8 \mu \mathrm{m}, \mathrm{SEM}=0.5 \mu \mathrm{m}, n=$ 8; Mira $^{+}: m=4.6 \mu \mathrm{m}, \mathrm{SEM}=0.6 \mu \mathrm{m}, n=8$ ). (N) Schematic depicting the localization of Nerfin-1 during larval and pupal neurogenesis. In larval stages (up to $96 \mathrm{~h} \mathrm{ALH),} \mathrm{Nerfin-1} \mathrm{is} \mathrm{expressed} \mathrm{in} \mathrm{neurons} \mathrm{(which} \mathrm{also} \mathrm{express} \mathrm{the} \mathrm{differentiation} \mathrm{marker} \mathrm{Pros)} \mathrm{and} \mathrm{not} \mathrm{in} \mathrm{self-renewing}$ NBs or GMCs. At the end of neurogenesis (120 h ALH), Nerfin-1 and Pros are localized to the nucleus of the NBs prior to their terminal differentiation. Bars: $E-H, 100 \mu \mathrm{m}$; all others, $10 \mu \mathrm{m}$. $\left(^{\star \star \star \star}\right) P \leq 0.0001$. See also Supplemental Figures S16, S17. 
differentiating pupal NBs typically do not (Homem et al. 2014). Consistent with this, we found that Nerfin-1 overexpression resulted in a reduction in the average diameter of NBs from 13.1 to $10.4 \mu \mathrm{m}$ (Fig. 6L). As NBs become progressively smaller with each cell cycle, they typically undergo size-symmetric terminal cell divisions (Maurange et al. 2008; Homem et al. 2014) preceded by nuclear Pros localization. Indeed, we found that Nerfin-1 overexpression led to nuclear Pros accumulation (Supplemental Fig. S17A-A') and an increased incidence of size-symmetric divisions (Fig. 6I,J, quantified in K). However, the growth regulator Myc was still expressed in these NBs (Supplemental Fig. S17B, $\left.\mathrm{B}^{\prime}\right)$. These results provide evidence that Nerfin-1 not only maintains the differentiated status of neurons but also promotes differentiation during neurogenesis (Fig. 6N).

\section{Discussion}

Growing evidence suggests that interconversion between differentiated cells and stem cells can account for initiation of glioblastoma in the mammalian brain (FriedmannMorvinski et al. 2012) and could be a general paradigm in cancer. Our data reveal an essential function for the zinc finger transcription factor Nerfin-1 in locking neurons into the differentiated state by preventing their reversion to NBs. This study focused mainly on type I NB lineages. We found that upon the loss of Nerfin-1, neurons undergo rapid cellular growth and reach a cell size threshold before a step-wise reversion process occurs. The reverted cells first switch on stem cell-specific genes (such as ase, dpn, and mira) while still maintaining the expression of neuronal genes (such as pros and elav). These cells with mixed neuronal/NB fates cycle slowly and occasionally undergo atypical size-symmetric divisions. As they further increase in size, neuronal genes are eventually switched off, and the reverted progenitors begin to cycle at the speed of wild-type NBs and undergo asymmetric selfrenewal. This expansion of neural progenitors results in proliferative tumorous masses that fail to differentiate and persist into adulthood (Fig. 7). With time, the homeostasis in these tumors becomes increasingly disrupted, eventually resulting in tumor masses consisting mostly of neural progenitors and few differentiated cells.

A similar reversion also occurs in type II mutant NB lineages. In the absence of Nerfin-1, neurons undergo stepwise reversion to give rise to ectopic $\mathrm{Ase}^{+}, \mathrm{Dpn}^{-}$ immature and then $\mathrm{Ase}^{+}, \mathrm{Dpn}^{+}$mature INPs by $120 \mathrm{~h}$ ALH. We found that, as reported (Weng et al. 2010; Homem et al. 2013), the transition from an immature to a mature INP (capable of divisions) takes several hours, and the delay in INP maturation could partially account for the subtle overgrowth phenotype that we observed for nerfin-1 ${ }^{159}$ type II lineages. Unlike linages mutant for tumor suppressors such as brat, numb/ $\operatorname{Notch}^{A C T}$, and erm, which contain multiple NBs derived from dedifferentiated INPs and generate large

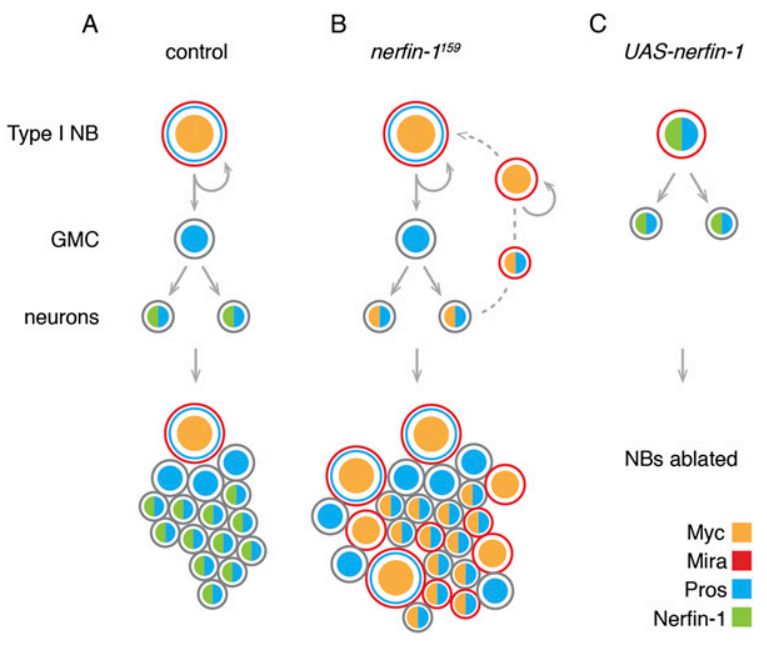

Figure 7. Nerfin-1 promotes differentiation and prevents neuronal reversion into neuroblasts. (A) Type I NBs express Mira (red) and Myc (orange) and segregate the homeodomain transcription factor Pros (blue) to the GMC. GMCs divide only once to produce two post-mitotic neurons that express Nerfin-1 (green). (B) Upon the loss of Nerfin-1 in neurons, Myc-dependent cellular growth ensures that neurons reach a cell size threshold before they undergo a stepwise reversion. The reverted cells first switch on stem cell-specific genes such as Mira while maintaining the expression of neuronal genes such as Pros. As these reverted NBs further increase in size, Pros is eventually switched off, and the reverted progenitors begin to cycle at the speed of wild-type neuroblasts and undergo asymmetric selfrenewal. This expansion of neural progenitors results in proliferative tumorous masses that consist of a mixture of neurons and NBs undergoing various stages of reversion. (C) When ectopically expressed earlier during development, Nerfin-1 promotes premature neuroblast cell cycle exit via size-symmetric cell divisions.

type II tumors (Lee et al. 2006a,b; Wang et al. 2006; Bowman et al. 2008; Weng et al. 2010; San-Juán and Baonza 2011; Xiao et al. 2012; Zacharioudaki et al. 2012), nerfin- $1^{159}$ type II mutant clones, similar to pros (Supplemental Fig. S5O; Bowman et al. 2008; Weng et al. 2010), contain only one $\mathrm{Ase}^{-}, \mathrm{Dpn}^{+} \mathrm{NB}$ despite an expansion of INPs. As Nerfin-1 is only expressed in differentiated neurons and not in the INPs, we think it is unlikely to play a role in INP specification, accounting for why its loss failed to result in INP-to-NB reversion. However, it remains possible that full reversion from neuron to type II NB takes longer than our experimental period.

\section{Nerfin-1 acts independently of Pros to promote differentiation in neurons}

In contrast to other factors that have been shown to regulate neuronal differentiation through modulation of the prodifferentiation transcription factor Pros (Carney et al. 2013) or act redundantly with Pros itself (Southall et al. 2014), we show that Nerfin-1 is sufficient to cause complete neuron-to-NB conversion in type I lineages independently of Pros. Nerfin-1 and Pros act in different 
cell types (neurons and GMCs, respectively). In the neurons, it is the loss of Nerfin-1 (this study) and not Pros (Carney et al. 2013) that is sufficient to induce reversion to NBs. However, many genes are commonly deregulated in nerfin- $1^{159}$ and pros $^{17}$ tumors, and they share several direct targets to promote differentiation and repress self-renewal. Consistent with this, our rescue experiment suggests that Pros has the ability to partially compensate for loss of Nerfin-1, forcing ectopic stem cells to differentiate. Furthermore, Nerfin-1, like Pros, acts as both an activator and a repressor; thus, cofactors may be required to provide specificity to Nerfin-1 function.

Nerfin-1 is required for timely NB cell cycle exit, and ectopic nerfin-1 promotes premature differentiation

Besides maintaining the differentiated status of neurons, Nerfin-1 is also involved in promoting terminal differentiation at the end of neurogenesis. Its expression in the NB nucleus at $120 \mathrm{~h} \mathrm{ALH} \mathrm{not} \mathrm{only} \mathrm{colocalizes} \mathrm{with} \mathrm{that}$ of Pros, previously shown to be required in this process (Choksi et al. 2006; Maurange et al. 2008), but seems to precede it, with a significant proportion of NBs expressing nuclear Nerfin-1 but not Pros. Moreover, in the absence of Nerfin-1, NBs fail to undergo Pros-dependent terminal divisions and persist into adulthood. When Nerfin-1 is ectopically expressed, NBs fail to maintain their cellular volume and undergo premature cell cycle exit via a size-symmetric division (Fig. 7C). In mice, medaka, zebrafish, and Caenorhabditis elegans (Wu et al. 2001; Candal et al. 2007; Farkas et al. 2008; ForbesOsborne et al. 2013), it has been shown that Nerfin-1 homologs are expressed in the CNS and play a role in neuronal differentiation, confirming that Nerfin-1 function is evolutionarily conserved.

nerfin-1 tumor growth is facilitated by Mycand Tor-mediated mechanisms

Both our immunostaining and live-imaging analysis of nerfin- $1^{159}$ type I lineages demonstrated that dedifferentiated nerfin- $1^{159}$ neurons undergo cellular volume increase, and this process is mediated by the global growth regulators Myc (Johnston et al. 1999) and Tor (Hennig and Neufeld 2002). At early stages of nerfin-1 tumor initiation, the up-regulation of Myc preceded the diminished expression of differentiation markers and increased expression of stem cell markers. In our ChIP analysis, we identified Myc as a direct target of Nerfin-1, confirming that the repression of Myc is likely to be key in maintaining differentiation. These results are also in line with a previously published study in which the investigators showed that in type II NBs, dedifferentiation of INPs to NBs is dependent on translational elongation factor Eif4e and Myc-mediated ribosomal cellular growth (Song and Lu 2011). Myc is indeed an important transcriptional regulator of "stemness" in the generation of induced pluripotent stem cells (Takahashi and Yamanaka 2006) and has been directly implicated in initiation of dedifferentiation in pancreatic cancers (Ischenko et al. 2013).
Our data illustrate that deregulation of a single transcription factor, Nerfin-1, is sufficient to induce brain tumor formation in post-mitotic neurons, and overexpression of Nerfin-1 results in premature differentiation. Our results strongly support the model of bidirectional interconvertibility between stem cells and differentiated cells rather than the strict and irreversible stem cell differentiation hierarchy.

\section{Materials and methods}

\section{Fly strains}

Larvae were raised on standard medium at $25^{\circ} \mathrm{C}$. We used the following strains for generating CNS clones using the MARCM system (Lee and Luo 2001): (1) (3L) w, tub-Gal4, UAS-nlsGFP:: 6xmyc::NLS, hs-flp; FRT2A, tubP-Gal80LL9/TM6b, (2) (3L) yw, hs-flp; tub-Gal4, UASmCD8GFP/CyO; FRT2A, tub-Gal80/ TM6b, (3) (3R) w, tub-Gal4, UAS-nlsGFP::6xmyc::NLS, hs-flp; FRT82b, tubP-Gal80 LL3/TM6b, and (4) (3R) yw, hs-flp; UAS-myrRFP, tub-Gal4, FRT82B, tub-Gal80/TM6b. W; FRT2A was used to generate control MARCM clones, $W_{;} ; F R T 2 A$, $D f(3 L)$ nerfin-1 ${ }^{159} /$ TM6b (Kuzin et al. 2005) was used to generate nerfin- $1^{159}$ clones, and $w_{;} ;$FRT $82 B$, pros ${ }^{17} / T M 3$ to generate pros $^{17}$ clones (Bloomington Stock Center).

w, UAS-Dcr2; Wor-Gal4, Ase-Gal80/CyO; UAS-myrRFP was used to mark wild-type type II lineages.

Flp-out clones were generated using yw, hs-flp;; act5>CD2>Gal4, UAS-GFP. Other genetic elements used were UAS-nerfin-1 and P[nerfin-1.GFP-NLS.SV-40] iA (Nerfin-1-GFP protein reporter), all from Kuzin et al. (2005); UAS-myc RNAi (KK106066, Vienna Drosophila RNAi Center [VDRC]); UAS-Tor ${ }^{D N}$ (Hennig and Neufeld 2002); UAS-rag ${ }^{D N}$ (Kim et al. 2008); UAS-raptorRNAi (TRiP 41912, Bloomington Stock Center); UAS-prosRNAi (TRiP 42538, Bloomington Stock Center); and $w$; nerfin-1-GFP/CyO; HisRFP/TM6b. Pan-neuroblast (UAS-Dcr2; dnab-Gal4, Bloomington Stock Center) overexpression of UAS-nerfin-1 (two copies, one located on chromosome II, and one located on chromosome III; kind gift of A. Kuzin) was performed at $29^{\circ} \mathrm{C}$. Animals were dissected at either $96 \mathrm{~h}$ or $110 \mathrm{~h} \mathrm{ALH}$.

\section{Immunostaining}

Larval tissues were fixed for $20 \mathrm{~min}$ in $4 \%$ formaldehyde/phosphate-buffered saline (PBS) and immunostained as described (Bello et al. 2003). The primary antibodies used were rabbit anti-aPKC (1:500; Santa Cruz Biotechnology), mouse anti-Mira (1:50; gift of A. Gould), rat anti-pH3 (1:500; Abcam), chick anti-GFP (1:2000; Abcam), rabbit anti-Dpn (1:100; gift of Y.N. Jan), guinea pig antiDpn (1:1000; gift of James Skeath), rat anti-Pros (1:50; gift of F. Matsuzaki), rabbit anti-Ase (1:50; gift of F. Matsuzaki), rat antiCycE (1:500; gift of Helena Richardson), mouse anti-CycA (1:50; Developmental Studies Hybridoma Bank), mouse or rat anti-Elav (1:100; Developmental Studies Hybridoma Bank), rabbit anti-Insc (1:1000; gift of W. Chia), rabbit anti-Myc (1:100; Santa Cruz Biotechnology), guinea pig anti-Nerfin-1 (1:5000; gift of A. Kuzin), rabbit anti-RFP (1:100; Abcam), and mouse anti-Fib (1:200; Abcam). Secondary goat antibodies conjugated to Alexa488, Alexa568, Alexa650, and Alexa505 (Molecular Probes) were used at 1:200. Images were collected on a Leica SP5 confocal microscope, and all images shown are single sections unless otherwise stated.

\section{Clone induction}

To induce MARCM clones for both the CNS and wing discs, larvae were heat-shocked $24 \mathrm{~h} \mathrm{ALH}$ for 12 or $15 \mathrm{~min}$ at $37^{\circ} \mathrm{C}$ and 
dissected $96 \mathrm{~h}$ later unless otherwise stated. For the 24-h time point in Figure 3, animals were heat-shocked $48 \mathrm{~h} \mathrm{ALH}$ and dissected $24 \mathrm{~h}$ later. MARCM clones in the adult VNC were obtained by heat-shocking larvae $24 \mathrm{~h} \mathrm{ALH}$ for $15 \mathrm{~min}$ at $37^{\circ} \mathrm{C}$, and flies were dissected $3 \mathrm{~d}$ after eclosion.

\section{EdU pulse chase}

Control or nerfin- $1^{159}$ clones were induced $24 \mathrm{~h}$ ALH. Twentyfour hours after clone induction, larvae were fed with $100 \mu \mathrm{g} / \mathrm{mL}$ EdU (Lee et al. 2006b) for $4 \mathrm{~h}$. They were then transferred to standard medium for a 24-h EdU-free chase. Larvae were dissected and processed for antibody staining, and incorporated EdU was detected by Click-iT fluorescent dye azide reaction.

\section{Live imaging}

For whole-brain imaging, dissected brains were cultured in primary cell culture medium as described by Harzer et al. (2013) and imaged using Leica SP5 and Nikon C2 microscopes following the protocol published in Aldaz et al. (2010). For dissociated neuronal cell imaging, control and nerfin- $1^{159}$ clones were induced $24 \mathrm{~h} \mathrm{ALH}$, the thoracic region of the CNS containing clones was dissected $72 \mathrm{~h}$ later, and imaging was performed on the Leica SP5 with resonance scanner following the published protocol in Aldaz et al. (2010).

\section{Cell cycle speed determination}

The number of cells in $\mathrm{M}$ phase of the cell cycle stained with $\mathrm{pH} 3$ was calculated as a percentage of total number of NBs to determine the speed of the cell cycle.

\section{Volume measurements}

Clone volume of NB lineages was measured from three-dimensional reconstructions of $1.5-\mu \mathrm{m}$ spaced confocal $\mathrm{Z}$ stacks with Volocity software (Improvision) or Imaris (Bitplane). Cellular, nuclear, and nucleolar volumes were estimated with the formula $4 / 3 \pi r^{3}$, with $r$ measured from single confocal sections using the Leica LAS software to average orthogonal measurements of cell diameter $(2 r)$. Neuroblast diameter was measured from a single confocal section using Volocity software. For histograms, error bars represent SEM, and $P$-values were calculated assuming equal sample variance using two-tailed Student's $t$-tests with equal sample variance.

\section{Transplantation assay}

Brain fragments of $\mathrm{GFP}^{+}$nerfin- $1^{159}$ and control MARCM clones were transplanted into the abdomen of naive hosts as previously described (Caussinus and Gonzalez 2005).

\section{Cell dissociation, FACS, and RNA-seq}

Third instar larvae carrying control, nerfin- $1^{159}$, and pros $^{17}$ clones were dissected, dissociated, and subjected to FACS sorting as described in Berger et al. (2012). Total RNA from sorted cells was isolated using TRIzol reagent (Invitrogen) and extracted with RNAeasy minikit (Quiagen); poly(A) mRNA was fragmented and transcribed into first and second strand complementary DNA (cDNA). The Illumina library was prepared according to standard protocols (TruSeq, Illumina). Nine libraries were indexed in a full lane of an Illumina HiSeq flow cell. Approximately 20 million paired-end 50-base-pair (bp) reads were generated for each sample. Sequence reads were aligned to the Drosophila melanogaster reference genome (release 5) using TopHat 2 (Kim et al. 2013). Genes were filtered from downstream analysis if they failed to achieve a CPM (counts per million mapped reads) value of at least one in at least two libraries. Counts were transformed to $\log _{2}$ counts per million and precision-weighted with the voom function of the limma package (Smyth 2005; Law et al. 2014). A linear model was fitted to each gene, and empirical Bayesmoderated $t$-statistics were used to assess differences in expression (Smyth 2004). Genes were called differentially expressed if they achieved a false discovery rate (FDR) of $<0.05$ and also an expression change of greater than twofold. Heat maps include top differentially expressed genes (smallest FDRs) that were identified by comparing nerfin-1 mutant cells with control cells and have expression levels >8 RPKMs (reads per exonic kilobase per million mapped reads) in either mutant or control or both. The heat maps show $\log _{2}$ RPKM expression values of the top 50 most differentially expressed genes. Expression values that were $<0$ were set to 0 . The complete list of differentially expressed genes is in Supplemental Table 1.

\section{Real-time PCR}

To validate the RNA-seq results, RNA was obtained as described above, and cDNA was produced with SuperScript III reverse transcriptase (Life Technologies) according to the manufacturer's instructions and amplified using the stepOnePlus real-time PCR system (Applied Biosystems) using Fast SYBR Green master mix reagent (Applied Biosystems). Samples were normalized to $\alpha$-actinin, and expression levels were calculated using the $2^{-\Delta \mathrm{Ct}}$ method. For primers, see Supplemental Table 2.

\section{ChIP}

Third instar Nerfin-1-GFP larvae were dissected in cold PBS, and the brains were isolated and fixed in $1 \mathrm{~mL}$ of $1.8 \%$ formaldehyde for $20 \mathrm{~min}$. Cross-linking was stopped by washing with $1 \mathrm{~mL}$ of fix stop solution (125 mM glycine in PBS) for $5 \mathrm{~min}$ followed by two washes in cold PBS. Approximately 300 brains were pooled together in 300 $\mu \mathrm{L}$ of lysis buffer (50 mM Tris- $\mathrm{HCl}$ at $\mathrm{pH} 8.0), 10 \mathrm{mM}$ ethylenediaminetetraacetic acid (EDTA), 1\% sodium sodecyl sulfate (SDS), and $1 \times$ protease inhibitor cocktail (P2714, Sigma). Sonication was carried out using a Covaris S2 sonicator for $30 \mathrm{~min}$ (30 sec on and off cycles, 200 cycles per burst, intensity 4, duty $10 \%$ ). Following centrifugation $\left(13,000 \mathrm{~g}\right.$ for $5 \mathrm{~min}$ at $\left.4^{\circ} \mathrm{C}\right), 10 \%$ was set aside as input. Per ChIP, $10 \mu \mathrm{L}$ of antibodies was added (anti-GFP [ab290] and rabbit polyclonal IgG [ab27478, Abcam]) and incubated overnight at $4^{\circ} \mathrm{C}$ on a rotator. Immunocomplexes were collected by adding $50 \mu \mathrm{L}$ of precleared, protein-A coated magnetic Dynabeads (catalog no. 10006D, Life Technologies) and incubated overnight at $4^{\circ} \mathrm{C}$. The beads were washed twice in $1 \mathrm{~mL}$ of wash buffer $(0.1 \%$ SDS, $1 \%$ Triton X-100, 2 mM EDTA, $150 \mathrm{mM} \mathrm{NaCl}, 20 \mathrm{mM}$ Tris$\mathrm{HCl})$ and once with final wash buffer $(0.1 \%$ SDS, $1 \%$ Triton X-100, $2 \mathrm{mM}$ EDTA, $500 \mathrm{mM} \mathrm{NaCl}, 20 \mathrm{mM}$ Tris-HCl). Immunoprecipitated chromatin was eluted twice in $100 \mu \mathrm{L}$ of elution buffer $(1 \%$ SDS, $100 \mathrm{mM} \mathrm{NaHCO}_{3}$ ) and mixed in a thermomixer for $15 \mathrm{~min}$ at $30^{\circ} \mathrm{C}$. Chromatin was decross-linked overnight at $65^{\circ} \mathrm{C}$, and DNA was purified by RNase A (catalog no. 11119915001, Roche) treatment for $1 \mathrm{~h}$ at $37^{\circ} \mathrm{C}$ and then subsequently collected using a ChIP DNA Clean and Concentrator kit (catalog no. D5205, Zymo Research). Real-time PCR experiments were performed as described above, and primers were designed against the region 150-bp upstream of and downstream from the transcription initiation site. For primers, see Supplemental Table 3.

\section{Acknowledgments}

We thank Ward Odenwald, Thomas Brody, and Alex Kuzin for generously sharing extensive published and unpublished Nerfin-1 
reagents. The early part of this work was carried out by L.Y.C. in Alex Gould's laboratory at the National Institute for Medical Research, London. We thank him and his laboratory for their advice, support, and guidance. We thank Holger Apitz, Alex Gould, Kieran Harvey, Carole Poon, Helena Richardson, and Joep Vissers for critical reading of the manuscript. We are grateful to C. Doe, A. Gould, F. Matsuzaki, H. Richardson, K. Harvey, Y.N. Jan, J. Skeath, Bloomington Stock Center, and VDRC for reagents. We also thank OZDros for their special assistance in Drosophila stock quarantine; Peter MacCallum Cancer Institute Confocal Microscopy Core, FACS Core, and Genomics Core facilities for expert technical assistance; Mark Dawson for valuable technical advice on ChIP; and Fabrizio Pastori for graphical illustration assistance. This work was funded by the Australian National Health and Medical Research Council (APP1044704).

\section{References}

Aldaz S, Escudero LM, Freeman M. 2010. Live imaging of Drosophila imaginal disc development. Proc Natl Acad Sci 107: 14217-14222.

Bello BC, Hirth F, Gould AP. 2003. A pulse of the Drosophila Hox protein Abdominal-A schedules the end of neural proliferation via neuroblast apoptosis. Neuron 37: 209-219.

Bello B, Reichert H, Hirth F. 2006. The brain tumor gene negatively regulates neural progenitor cell proliferation in the larval central brain of Drosophila. Development 133: 2639-2648.

Bello BC, Izergina N, Caussinus E, Reichert H. 2008. Amplification of neural stem cell proliferation by intermediate progenitor cells in Drosophila brain development. Neural Dev 3: 5.

Berger C, Harzer H, Burkard TR, Steinmann J, van der Horst S, Laurenson A-S, Novatchkova M, Reichert H, Knoblich JA. 2012. FACS purification and transcriptome analysis of Drosophila neural stem cells reveals a role for Klumpfuss in selfrenewal. Cell Reports 2: 407-418.

Betschinger J, Mechtler K, Knoblich JA. 2006. Asymmetric segregation of the tumor suppressor brat regulates self-renewal in Drosophila neural stem cells. Cell 124: 1241-1253.

Boone JQ, Doe CQ. 2008. Identification of Drosophila type II neuroblast lineages containing transit amplifying ganglion mother cells. Dev Neurobiol 68: 1185-1195.

Bowman SK, Rolland V, Betschinger J, Kinsey KA, Emery G, Knoblich JA. 2008. The tumor suppressors Brat and Numb regulate transit-amplifying neuroblast lineages in Drosophila. Dev Cell 14: 535-546.

Bush A, Hiromi Y, Cole M. 1996. Biparous: a novel bHLH gene expressed in neuronal and glial precursors in Drosophila. Dev Biol 180: 759-772.

Candal E, Alunni A, Thermes V, Jamen F, Joly J-S, Bourrat F. 2007. Ol-insm1b, a SNAG family transcription factor involved in cell cycle arrest during medaka development. Dev Biol 309: 1-17.

Carney TD, Struck AJ, Doe CQ. 2013. midlife crisis encodes a conserved zinc-finger protein required to maintain neuronal differentiation in Drosophila. Development 140: 4155-4164.

Caussinus E, Gonzalez C. 2005. Induction of tumor growth by altered stem-cell asymmetric division in Drosophila melanogaster. Nat Genet 37: 1125-1129.

Choksi SP, Southall TD, Bossing T, Edoff K, de Wit E, Fischer BE, van Steensel B, Micklem G, Brand AH. 2006. Prospero acts as a binary switch between self-renewal and differentiation in Drosophila neural stem cells. Dev Cell 11: 775-789.

de la Cova C, Johnston LA. 2006. Myc in model organisms: a view from the flyroom. Semin Cancer Biol 16: 303-312.
Doe CQ, Chu-LaGraff Q, Wright DM, Scott MP. 1991. The prospero gene specifies cell fates in the Drosophila central nervous system. Cell 65: 451-464.

Farkas LM, Haffner C, Giger T, Khaitovich P, Nowick K, Birchmeier C, Pääbo S, Huttner WB. 2008. Insulinomaassociated 1 has a panneurogenic role and promotes the generation and expansion of basal progenitors in the developing mouse neocortex. Neuron 60: 40-55.

Forbes-Osborne MA, Wilson SG, Morris AC. 2013. Insulinomaassociated 1a (Insm1a) is required for photoreceptor differentiation in the zebrafish retina. Dev Biol 380: 157-171.

Friedmann-Morvinski D, Bushong EA, Ke E, Soda Y, Marumoto T, Singer O, Ellisman MH, Verma IM. 2012. Dedifferentiation of neurons and astrocytes by oncogenes can induce gliomas in mice. Science 338: 1080-1084.

Harzer H, Berger C, Conder R, Schmauss G, Knoblich JA. 2013. FACS purification of Drosophila larval neuroblasts for nextgeneration sequencing. Nat Protoc 8: 1088-1099.

Hennig KM, Neufeld TP. 2002. Inhibition of cellular growth and proliferation by dTOR overexpression in Drosophila. Genesis 34: $107-110$.

Homem CCF, Knoblich JA. 2012. Drosophila neuroblasts: a model for stem cell biology. Development 139: 4297-4310.

Homem CCF, Reichardt I, Berger C, Lendl T, Knoblich JA. 2013. Long-term live cell imaging and automated 4D analysis of Drosophila neuroblast lineages. PLOS ONE 8: e79588.

Homem CCF, Steinmann V, Burkard TR, Jais A, Esterbauer H, Knoblich JA. 2014. Ecdysone and mediator change energy metabolism to terminate proliferationin Drosophila neural stem cells. Cell 158: 874-888.

Ischenko I, Zhi J, Moll UM, Nemajerova A, Petrenko O. 2013. Direct reprogramming by oncogenic Ras and Myc. Proc Natl Acad Sci 110: 3937-3942.

Johnston LA, Prober DA, Edgar BA, Eisenman RN, Gallant P. 1999. Drosophila myc regulates cellular growth during development. Cell 98: 779-790.

Kim E, Goraksha-Hicks P, Li L, Neufeld TP, Guan K-L. 2008. Regulation of TORC1 by Rag GTPases in nutrient response. Nat Cell Biol 10: 935-945.

Kim D, Pertea G, Trapnell C, Pimentel H, Kelley R, Salzberg SL. 2013. TopHat2: accurate alignment of transcriptomes in the presence of insertions, deletions and gene fusions. Genome Biol 14: R36.

Kuzin A, Brody T, Moore AW, Odenwald WF. 2005. Nerfin-1 is required for early axon guidance decisions in the developing Drosophila CNS. Dev Biol 277: 347-365.

Kuzin A, Kundu M, Brody T, Odenwald WF. 2007. The Drosophila nerfin-1 mRNA requires multiple microRNAs to regulate its spatial and temporal translation dynamics in the developing nervous system. Dev Biol 310: 35-43.

Law CW, Chen Y, Shi W, Smyth GK. 2014. Voom: precision weights unlock linear model analysis tools for RNA-seq read counts. Genome Biol 15: R29.

Lee G, Chung J. 2007. Discrete functions of rictor and raptor in cell growth regulation in Drosophila. Biochem Biophys Res Commun 357: 1154-1159.

Lee T, Luo L. 2001. Mosaic analysis with a repressible cell marker (MARCM) for Drosophila neural development. Trends Neurosci 24: 251-254.

Lee CY, Andersen RO, Cabernard C, Manning L, Tran KD, Lanskey MJ, Bashirullah A, Doe CQ. 2006a. Drosophila Aurora-A kinase inhibits neuroblast self-renewal by regulating aPKC/Numb cortical polarity and spindle orientation. Genes Dev 20: 3464-3474.

Lee CY, Wilkinson BD, Siegrist SE, Wharton RP, Doe CQ. 2006b. Brat is a Miranda cargo protein that promotes neuronal 
differentiation and inhibits neuroblast self-renewal. Dev Cell 10: 441-449.

Liu W-D, Wang H-W, Muguira M, Breslin MB, Lan MS. 2006. INSM1 functions as a transcriptional repressor of the neuroD/ $\beta 2$ gene through the recruitment of cyclin D1 and histone deacetylases. Biochem J 397: 169-177.

Maurange C, Cheng L, Gould AP. 2008. Temporal transcription factors and their targets schedule the end of neural proliferation in Drosophila. Cell 133: 891-902.

Rhyu MS, Jan LY, Jan YN. 1994. Asymmetric distribution of numb protein during division of the sensory organ precursor cell confers distinct fates to daughter cells. Cell 76: 477-491.

San-Juán BP, Baonza A. 2011. The bHLH factor deadpan is a direct target of Notch signaling and regulates neuroblast self-renewal in Drosophila. Dev Biol 352: 70-82.

Schwitalla S, Fingerle AA, Cammareri P, Nebelsiek T, Göktuna SI, Ziegler PK, Canli O, Heijmans J, Huels DJ, Moreaux G, et al. 2013. Intestinal tumorigenesis initiated by dedifferentiation and acquisition of stem-cell-like properties. Cell 152: 25-38.

Smyth GK. 2004. Linear models and empirical Bayes methods for assessing differential expression in microarray experiments. Stat Appl Genet Mol Biol 3: 1-25.

Smyth GK. 2005. limma: linear models for microarray data. In Bioinformatics and computational biology solutions using $R$ and Bioconductor (ed. Genteman R, et al.), pp. 397-420, Springer-Verlag, New York.

Song Y, Lu B. 2011. Regulation of cell growth by Notch signaling and its differential requirement in normal vs. tumor-forming stem cells in Drosophila. Genes Dev 25: 2644-2658.

Southall TD, Davidson CM, Miller C, Carr A, Brand AH. 2014. Dedifferentiation of neurons precedes tumor formation in Lola mutants. Dev Cell 28: 685-696.

Spana EP, Doe CQ. 1995. The prospero transcription factor is asymmetrically localized to the cell cortex during neuroblast mitosis in Drosophila. Development 121: 3187-3195.

Stivers C, Brody T, Kuzin A, Odenwald WF. 2000. Nerfin-1 and -2, novel Drosophila $\mathrm{Zn}$-finger transcription factor genes expressed in the developing nervous system. Mech Dev 97: 205-210.

Takahashi K, Yamanaka S. 2006. Induction of pluripotent stem cells from mouse embryonic and adult fibroblast cultures by defined factors. Cell 126: 663-676.

Vaessin H, Grell E, Wolff E, Bier E, Jan LY, Jan YN. 1991. prospero is expressed in neuronal precursors and encodes a nuclear protein that is involved in the control of axonal outgrowth in Drosophila. Cell 67: 941-953.

Wang H, Somers GW, Bashirullah A, Heberlein U, Yu F, Chia W. 2006. Aurora-A acts as a tumor suppressor and regulates selfrenewal of Drosophila neuroblasts. Genes Dev 20: 34533463.

Weng M, Golden KL, Lee C-Y. 2010. dFezf/Earmuff maintains the restricted developmental potential of intermediate neural progenitors in Drosophila. Dev Cell 18: 126-135.

Wu J, Duggan A, Chalfie M. 2001. Inhibition of touch cell fate by egl-44 and egl-46 in C. elegans. Genes Dev 15: 789-802.

Xiao Q, Komori H, Lee C-Y. 2012. klumpfuss distinguishes stem cells from progenitor cells during asymmetric neuroblast division. Development 139: 2670-2680.

Zacharioudaki E, Magadi SS, Delidakis C. 2012. bHLH-O proteins are crucial for Drosophila neuroblast self-renewal and mediate Notch-induced overproliferation. Development 139: $1258-1269$. 


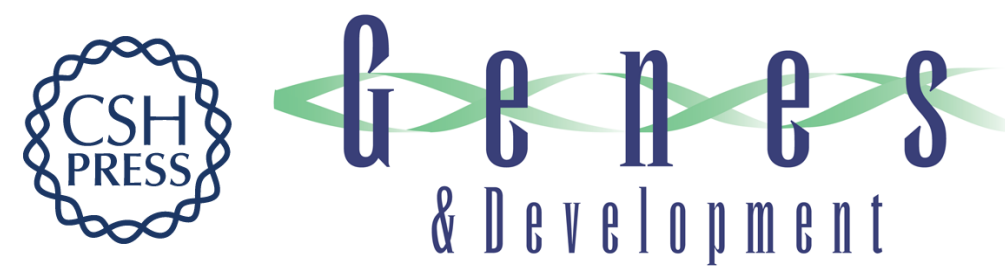

\section{The transcription factor Nerfin-1 prevents reversion of neurons into neural stem cells}

Francesca Froldi, Milan Szuperak, Chen-Fang Weng, et al.

Genes Dev. 2015, 29:

Access the most recent version at doi:10.1101/gad.250282.114

\section{Supplemental http://genesdev.cshlp.org/content/suppl/2015/01/15/29.2.129.DC1 Material}

References This article cites 51 articles, 14 of which can be accessed free at: http://genesdev.cshlp.org/content/29/2/129.full.html\#ref-list-1

Creative This article is distributed exclusively by Cold Spring Harbor Laboratory Press for the first Commons six months after the full-issue publication date (see

License http://genesdev.cshlp.org/site/misc/terms.xhtml). After six months, it is available under a Creative Commons License (Attribution-NonCommercial 4.0 International), as described at http://creativecommons.org/licenses/by-nc/4.0/.

Email Alerting Receive free email alerts when new articles cite this article - sign up in the box at the top Service right corner of the article or click here.

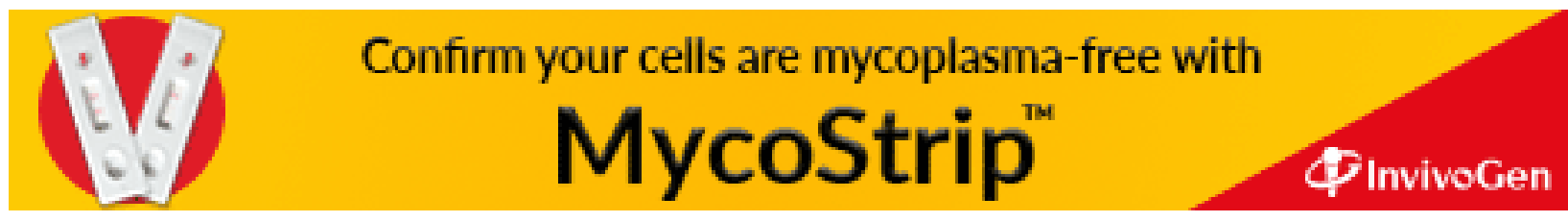

